
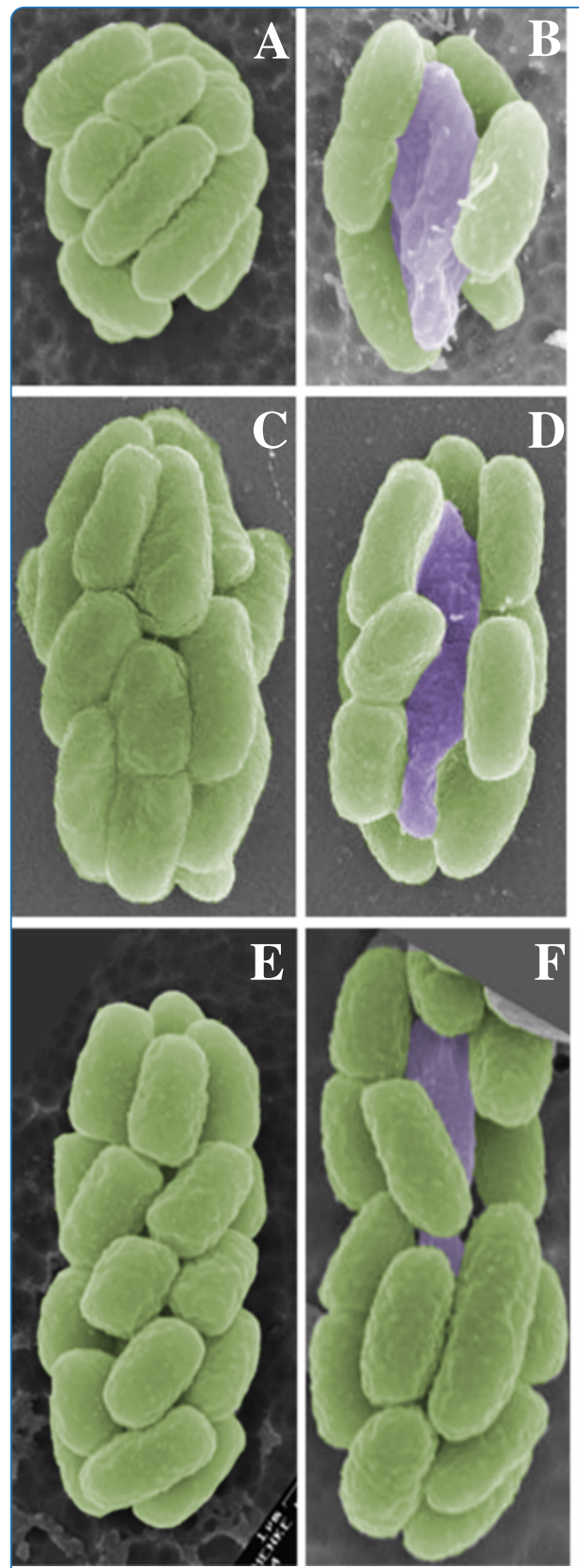
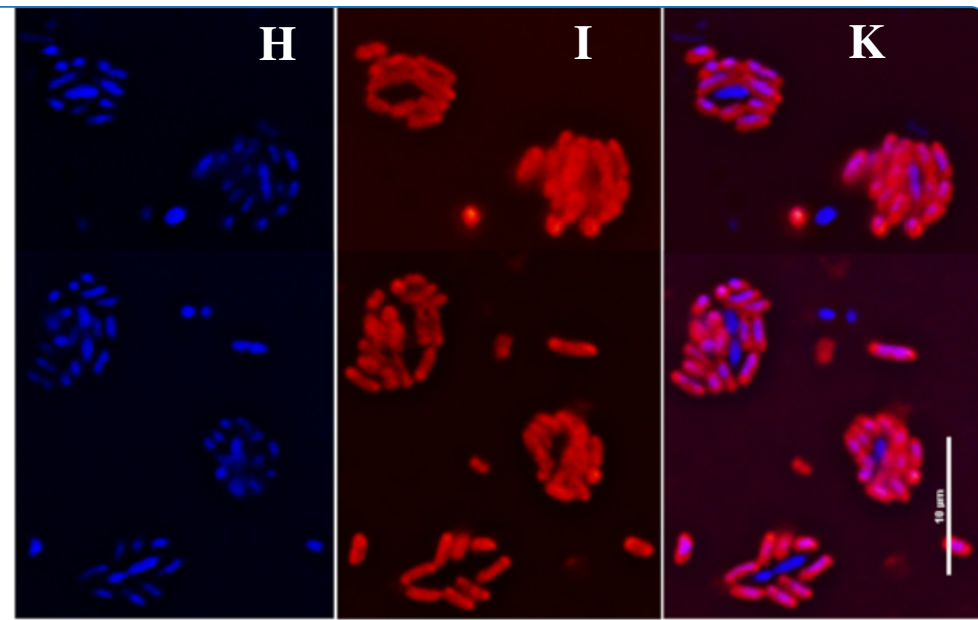

SEM (A-G) and epifluorescence (HK) photomicrographs of "Chlorochromatium aggregatum". Epibionts are shown in false color green, central bacteria in false color purple. (A) Consortium in an early stage of cell division, also seen in (B) with a partially uncovered central bacterium. (C and D) Consortia with elongated epibiont cells (C) and elongated central bacterium (D). (E, $\mathrm{F}$ and $\mathrm{G})$ Consortia during division into two daugther consortia. (F) consortium with partially and (G) entirely uncovered central bacterium. (H) Consortia stained with DAPI. (I) Micrograph showing the autofluorescence (Ex. $445 \mathrm{~nm}$, Em. $>740 \mathrm{~nm}$ ) of bacteriochlorophyll $c$ present in the epibiont chlorosomes. (K) Overlay of $\mathrm{H}$ and $\mathrm{I}$.

\title{
Genomic analysis reveals key aspects of prokaryotic symbiosis in the phototrophic consortium "Chlorochromatium aggregatum"
}

Liu et al. 


\title{
Genomic analysis reveals key aspects of prokaryotic symbiosis in the phototrophic consortium "Chlorochromatium aggregatum"
}

\author{
Zhenfeng Liư ${ }^{1,7}$, Johannes Müller², Tao Li ${ }^{1,8}$, Richard M Alvey ${ }^{1,9}$, Kajetan Vogl $^{1}$, Niels-Ulrik Frigaard ${ }^{3}$, \\ Nathan C Rockwell ${ }^{4}$, Eric S Boyd ${ }^{5}$, Lynn P Tomsho ${ }^{1}$, Stephan C Schuster ${ }^{1}$, Petra Henke ${ }^{2}$, Manfred Rohde 6 , \\ Jörg Overmann ${ }^{2}$ and Donald A Bryant ${ }^{1,5^{*}}$
}

\begin{abstract}
Background: 'Chlorochromatium aggregatum' is a phototrophic consortium, a symbiosis that may represent the highest degree of mutual interdependence between two unrelated bacteria not associated with a eukaryotic host. 'Chlorochromatium aggregatum' is a motile, barrel-shaped aggregate formed from a single cell of 'Candidatus Symbiobacter mobilis", a polarly flagellated, non-pigmented, heterotrophic bacterium, which is surrounded by approximately 15 epibiont cells of Chlorobium chlorochromatii, a non-motile photolithoautotrophic green sulfur bacterium.

Results: We analyzed the complete genome sequences of both organisms to understand the basis for this symbiosis. Chl. chlorochromatii has acquired relatively few symbiosis-specific genes; most acquired genes are predicted to modify the cell wall or function in cell-cell adhesion. In striking contrast, 'Ca. S. mobilis' appears to have undergone massive gene loss, is probably no longer capable of independent growth, and thus may only reproduce when consortia divide. A detailed model for the energetic and metabolic bases of the dependency of ' $\mathrm{Ca}$. S. mobilis' on Chl. chlorochromatii is described.

Conclusions: Genomic analyses suggest that three types of interactions lead to a highly sophisticated relationship between these two organisms. Firstly, extensive metabolic exchange, involving carbon, nitrogen, and sulfur sources as well as vitamins, occurs from the epibiont to the central bacterium. Secondly, 'Ca. S. mobilis' can sense and move towards light and sulfide, resources that only directly benefit the epibiont. Thirdly, electron cycling mechanisms, particularly those mediated by quinones and potentially involving shared protonmotive force, could provide an important basis for energy exchange in this and other symbiotic relationships.
\end{abstract}

\section{Background}

Symbiotic interactions between bacteria and eukaryotes are common and can be mutualistic (for example, between nitrogen-fixing Rhizobium spp. and legumes [1] or between sulfur-oxidizing Gamma- or Epsilonbacteria and marine invertebrates [2]) or parasitic (for example, bacterial pathogens and human hosts). Archaea and eukaryotes also form symbioses, which include the methanogens of arthropod,

\footnotetext{
*Correspondence: dab14@psu.edu

'Department of Biochemistry and Molecular Biology, The Pennsylvania State University, University Park, PA 16802, USA

${ }^{5}$ Department of Microbiology, Montana State University, Bozeman, MT 59717, USA

Full list of author information is available at the end of the article
}

ruminant, and human digestive systems as well as the archaeal symbionts of sponges [3]. Symbioses involving only bacterial and/or archaeal partners are also known and may be more widespread than commonly recognized [4]. Mutualistic interactions involving nutrient exchange, waste removal, and stress protection are probably crucial to the maintenance of microbial biofilm communities and are well documented in syntrophic interactions involving hydrogen or formate transfer [5]. Other examples include chlorophototrophic mat communities of hot springs [6] and anaerobic methane-oxidizing communities of marine environments [7].

The term 'consortium' originally described a close association of microbial cells in which two or more

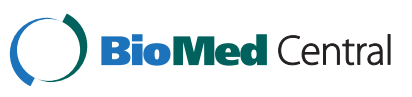

(C) 2013 Liu et al.; licensee BioMed Central Ltd. This is an open access article distributed under the terms of the Creative Commons Attribution License (http://creativecommons.org/licenses/by/2.0), which permits unrestricted use, distribution, and reproduction in any medium, provided the original work is properly cited. 
different microorganisms maintained an organized structure through permanent cell-to-cell contact [8]. Phototrophic consortia were first reported more than 100 years ago [9], and they may represent the highest degree of mutual interdependence between two unrelated bacteria not associated with a eukaryotic host [4,10-12]. Ten morphologically distinct types are known, and most are barrelshaped, motile aggregates comprising two cell types: a central bacterium, which is a single, non-pigmented, and heterotrophic cell carrying a single polar flagellum; and approximately 15 to $>40$ epibionts, which are greenor brown-colored green sulfur bacteria (GSB) [10-12] (Figure 1; Figure S1 in Additional file 1). These consortia are motile and exhibit scotophobotaxis ('fear of the dark') as well as positive chemotaxis to sulfide, thiosulfate, 2-oxoglutarate and citrate [13].

Because of the availability of an enrichment culture isolated from Lake Dagow, Germany, "Chlorochromatium aggregatum" is the best-characterized phototrophic consortium [13]. The epibiont of "Chlorochromatium aggregatum", Chlorobium (Chl.) chlorochromatii strain $\mathrm{CaD} 3$, is not obligately symbiotic. It has been isolated and grown axenically, and physiological characterization showed that Chl. chlorochromatii is similar to other free-living GSB isolates [14]. It is a non-motile, obligately anaerobic, photolithoautotrophic GSB that uses sulfide as the electron donor for

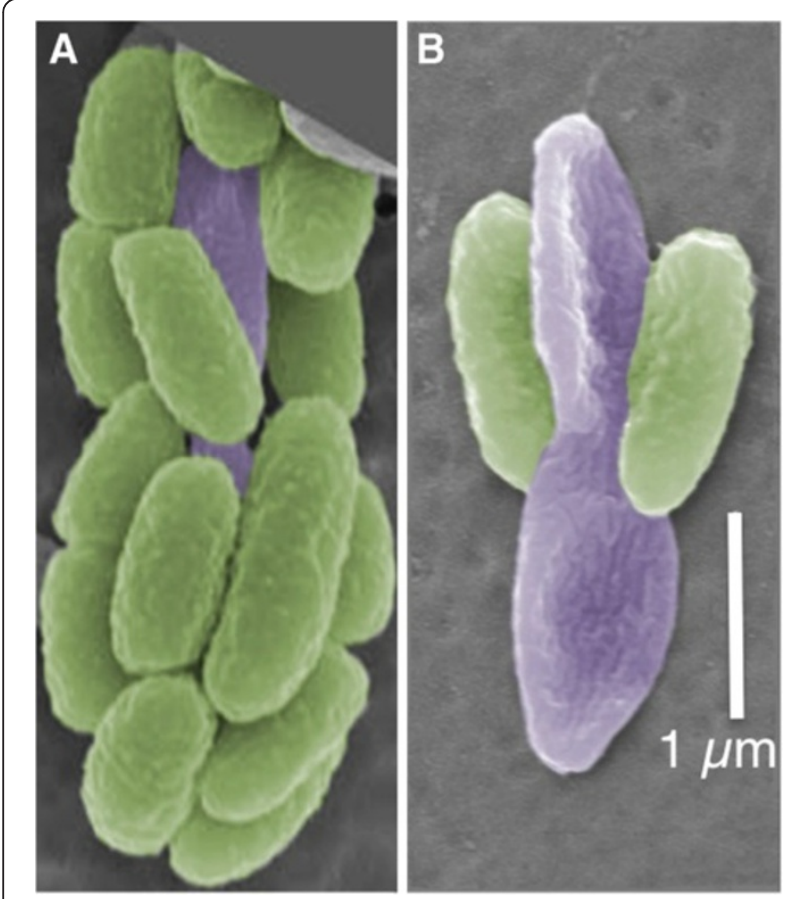

Figure 1 Scanning electron micrographs of "Chlorochromatium aggregatum". (A,B) Epibionts are shown in false color green, central bacteria in false color purple. (B) The central rod is dividing, and most of the epibiont cells have dissociated from the consortium. Scale bar in (B) equals $1 \mu \mathrm{m}$. photosynthetic $\mathrm{CO}_{2}$ and $\mathrm{N}_{2}$ fixation. The genome of Chl. chlorochromatii has been sequenced, and this enabled previous biochemical, transcriptomic and proteomic studies of Chl. chlorochromatii $[15,16]$. The central bacterium of "Chlorochromatium aggregatum", hereafter denoted as "Candidatus Symbiobacter ( $\mathrm{Ca}$. S.) mobilis", is a rod-shaped member of the Betaproteobacteria (Figure 1; Figure S1 in Additional file 1). It has a single polar flagellum [17] and is most similar to non-symbiotic bacteria of family Comamonadaceae [18]. All attempts to grow the central bacterium independently from the epibionts have failed. Phylogenetic analyses have shown that the epibionts and central bacteria of different types of consortia and lakes have polyphyletic origins [19-21]. To gain insights into the molecular basis for the symbiotic relationship in phototrophic consortia, we determined the complete genome sequence of "Ca. S. mobilis", analyzed these genomes, and present here a description of "Chlorochromatium aggregatum". Compared to free-living close relatives, "Ca. S. mobilis" has apparently undergone massive gene loss and is probably no longer capable of independent growth.

\section{Results and discussion}

\section{The two genomes of "Chlorochromatium aggregatum"}

The Chl. chlorochromatii genome (GenBank accession number CP000108) is a single circular DNA molecule of $2,572,079$ bp with a $\mathrm{G}+\mathrm{C}$ content of $44.3 \mathrm{~mol} \%$. It encodes 2,002 open reading frames (ORFs), one rRNA operon, and 45 tRNAs (Figure 2A). The size and gene content are very similar to those of 15 other GSB genomes [22]. Similar to the genomes of other GSB, the Chl. chlorochromatii genome encodes proteins for the photosynthetic apparatus, bacteriochlorophyll biosynthesis, sulfide oxidation, $\mathrm{CO}_{2}$ fixation via the reverse tricarboxylic acid (TCA) cycle, nitrogen fixation and all housekeeping genes of central metabolism and macromolecule biosynthesis [22-25]. Only 311 ORFs (15\%), nearly all of which encode proteins with unidentified functions, have no homologs in genomes of other GSB, which are not known to be involved in phototrophic consortia (Table S1 in Additional file 2). These results are consistent with the observation that Chl. chlorochromatii is not obligately symbiotic and can grow independently as a photolithoautotroph [14]. Thus, only relatively minor changes in gene content were apparently required as the epibiont adapted to a symbiotic lifestyle.

In contrast, the genome of the "Ca. S. mobilis" differs dramatically from the genomes of eight close relatives with sequenced genomes (listed in the Figure 2 legend). The "Ca. S. mobilis" genome (GenBank accession number CP004885) is a single circular DNA molecule of $2,991,840$ bp with $\mathrm{G}+\mathrm{C}$ content of $59.1 \mathrm{~mol} \%$. It has two tandemly repeated rRNA operons [21], 44 tRNAs and 2,626 proteins (Figure $2 \mathrm{~B}$ ). The closest non-symbiotic relatives of "Ca. S. mobilis" from the family Comamonadaceae 

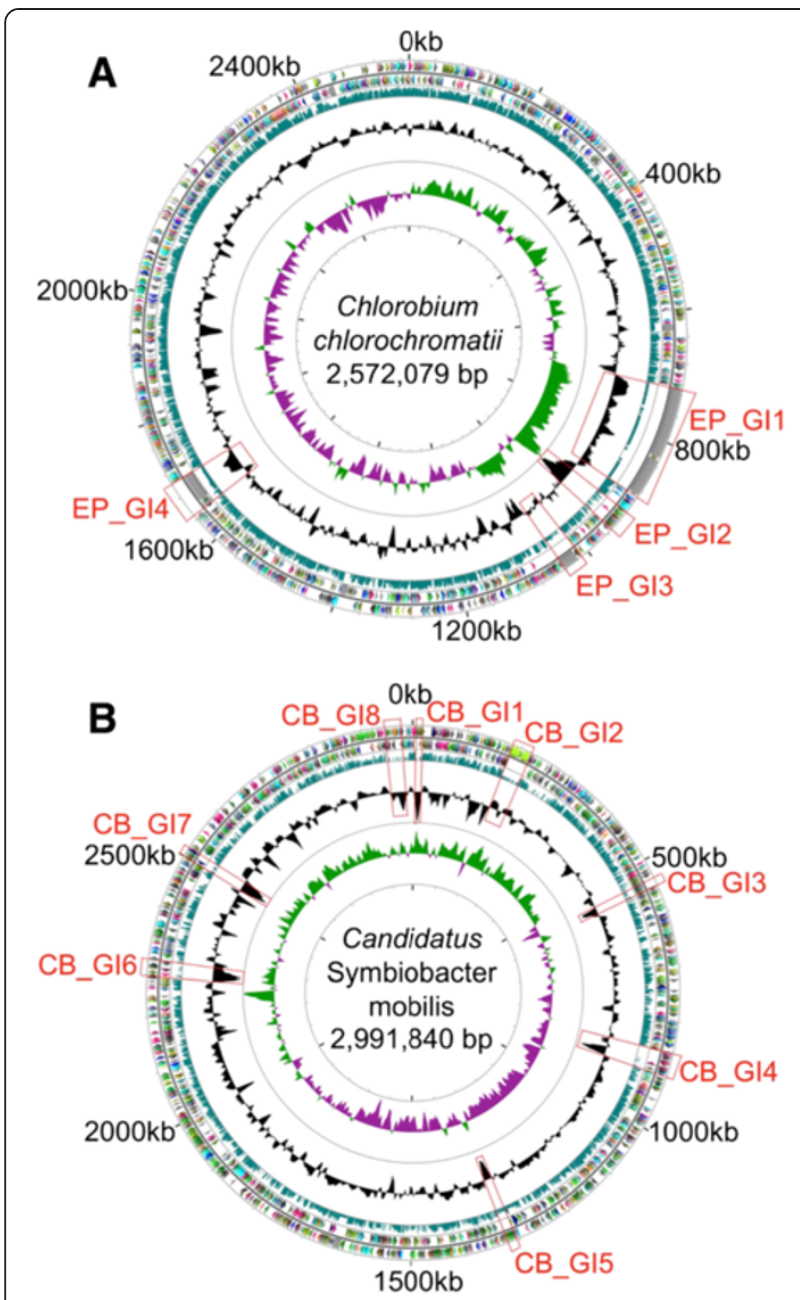

Figure 2 Circular maps and genomic islands of the genomes of Chl. chlorochromatii (A) and "Ca. S. mobilis" (B). From outside in, the circles represent open reading frames (ORFs) on the forward strand, ORFs on the reverse strand, BLASTP scores of ORFs against reference genomes, mol\% G $+\mathrm{C}$, and GC skew. Colors of ORFs represent COG (clusters of orthologous groups of proteins) categories. Mol\% $\mathrm{G}+\mathrm{C}$ is plotted using genome averages as baselines, which are $44.3 \%$ and $59.1 \%$ for the epibiont and the central bacterium, respectively. Genomic islands are marked by red boxes (see Materials and methods for identification of genomic islands). The reference genomes used in this study are: Chlorobaculum parvum NCIB 8327, Chlorobaculum tepidum ATCC 49652, Chlorobium ferrooxidans DSM 13031, Chlorobium limicola DSM 245, Chlorobium phaeobacteroides BS-1, Chlorobium phaeobacteroides DSM 266, Chlorobium phaeovibrioides DSM 265, Chlorobium clathratiforme DSM 5477, Chlorobium luteolum DSM 273, Prosthecochloris aestuarii DSM 271, and Chloroherpeton thalassium ATCC 35110 for Chl. chlorochromatii; Acidovorax avenae citrulli str. AACO0-1, Rhodoferax ferrireducens DSM 15236, Alicycliphilus denitrificans str. BC, Comamonas testosteroni str. CNB-2, Delftia acidovorans str. SPH-1, Polaromonas naphthalenivorans str. CJ2, Variovorax paradoxus str. EPS, and Verminephrobacter eiseniae str. EF01-2 for "Ca. S. mobilis."

have much larger genomes (4.8 to $6.8 \mathrm{Mbp}$ ). "Ca. S. mobilis" apparently underwent substantial gene loss during its evolution, especially for genes involved in metabolism (Figure 3). Eight free-living members of the family

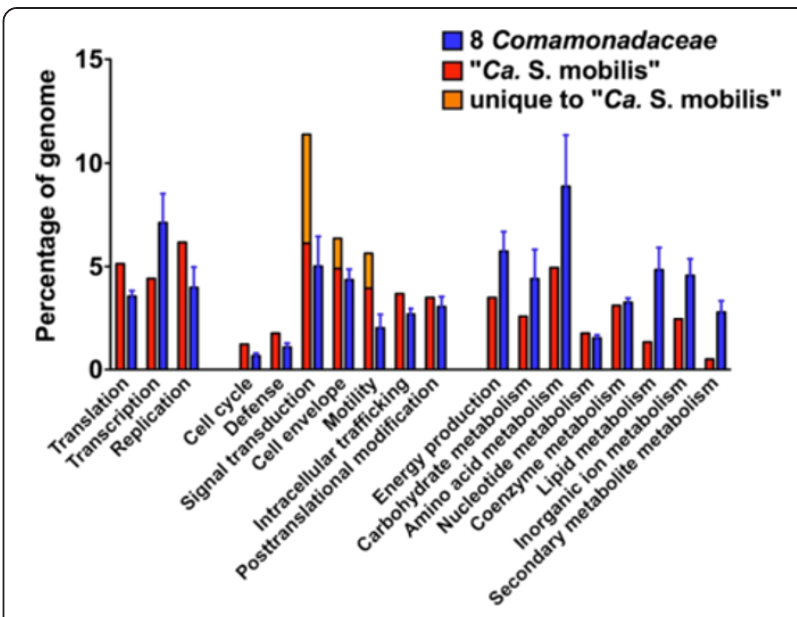

Figure 3 Comparison of gene contents of "Ca. S. mobilis" and its relatives based on functional categories. Percentages of genes for each COG category in the genomes are calculated for "Ca. S. mobilis" and its relatives based on COG assignment of genes provided by Integrated Microbial Genomes [28]. Averages and standard deviations of the percentages for the eight Comamonadaceae organisms listed in Figure 2 legend are shown.

Comamonadaceae, each representing a different genus, have a core genome of 1,284 genes, but 409 (32\%) of these genes are missing from the "Ca. S. mobilis" genome (for a list of these missing genes, see Table S2 in Additional file 2). This degree of gene loss, which is common in exclusively symbiotic organisms [26,27], supports the experimental observation that " $\mathrm{Ca}$. S. mobilis" is no longer capable of independent growth and now depends on its photoautotrophic partner for essential metabolites (see below).

On the other hand, "Ca. S. mobilis" has also acquired new genes, either through lateral gene transfer or gene duplication and subsequent diversification, that are not found in its close relatives. A comparison identified 1,055 "Ca. S. mobilis" genes without orthologs in any of eight free-living Comamonadaceae organisms; 444 (42\%) of these genes have annotations other than 'hypothetical protein' (for a complete list, see Table S3 in Additional file 2). Genes involved in signal transduction (138), cell envelope biogenesis (38) and cell motility (44) are overrepresented. These gains and losses of genes resulted in different functional compositions for the genomes of "Ca. S. mobilis" and its relatives, especially in the categories mentioned above (Figure 3). Such differences presumably reflect adaptations of "Ca. S. mobilis" to an obligately symbiotic lifestyle, and they suggest that the major roles of " $\mathrm{Ca}$. S. mobilis" are to sense the environment and to provide motility. The increased number of genes for cell wall and envelope biosynthesis is consistent with the importance of previously observed cell-to-cell contacts between the central rod and the epibionts via specialized cell-surface structures [17]. 


\section{Horizontal gene transfer}

The genomes of " $\mathrm{Ca}$. S. mobilis" and Chl. chlorochromatii were compared to search for potential horizontal gene transfers between these two partner organisms that are constantly in close contact. Thirteen pairs of genes in these two genomes are more similar to one another than to most if not all proteins in databases (Table S4 in Additional file 2); however, the functions of most could not be unambiguously assigned. Gene exchange (and gene transfer) between the two partners does not appear to have occurred frequently in this symbiosis.

The two genomes were also analyzed to identify genomic islands (GIs), which often harbor recently acquired or highly conserved genes. The identified GIs are marked in Figure 2 and their properties are summarized in Table 1 (GIs in Chl. chlorochromatii are denoted with the prefix 'EP'; GIs in "Ca. S. mobilis" are denoted with the prefix ' $C B$ '). Four genomic islands were identified in Chl. chlorochromatii, and three contain unusually large proteins. These proteins are similar to hemagglutinin and outer membrane adhesin proteins of the RTX toxin family, which contain numerous, internally repeated, calciumbinding domains [29]. ORFs Cag_0614 and Cag_0616 in EP_GI-1 predict proteins of 36,805 and 20,646 amino acids, respectively. The former protein is larger than human titin (34,350 amino acids), often considered to be the largest known protein [30]. These two genes are transcribed, encode symbiosis-specific proteins, and have been hypothesized to stabilize contacts between the central bacterium and epibiont cells [15]. Smaller but related proteins, including the ones in EP_GI-3 (Cag_0738) and EP_GI-4 (Cag_1242), could play similar roles.

Eight GIs were identified in the "Ca. S. mobilis" genome (Figure 2B). The presence of transposases and integrases in most of them suggests that they were probably acquired by horizontal gene transfer. Genes found in the GIs of $\mathrm{Chl}$. chlorochromatii, such as those involved in cell envelope biosynthesis and encoding haemagglutinin/adhesin-like proteins, were similarly found in CB_GI-1, CB_GI-2, CB_GI-3 and CB_GI-7. CB_GI-4 included mainly CRISPRassociated proteins and hypothetical proteins, while CB_GI-5 and CB_GI-7 contained mainly genes of unknown function. CB_GI-4 (Cenrod_1189-Cenrod_1205) encodes chemotaxis and regulatory proteins, and interestingly, this gene cluster is similar in both gene order and sequence to clusters found in several purple sulfur bacteria (for example, Allochromatium vinosum) (Figure S2B in Additional file 1). Purple sulfur bacteria are often found in the same lakes where phototrophic consortia occur [31], and the central bacterium may have acquired genes from such organisms. Although sequence analysis cannot determine the attractant or repellent molecule(s) sensed by the products of these genes, purple sulfur bacteria are often positively chemotactic to sulfide [32,33]. The horizontal acquisition of genes for sulfide chemotaxis from a sulfide-oxidizing bacterium could explain how "Chlorochromatium aggregatum" gained its known ability to sense and swim towards sulfide [13].

Compared to the genome average, EP_GI-2 has extremely low $\mathrm{G}+\mathrm{C}$ mol\% and includes two genes encoding transposases or integrases, which suggests that these genes were laterally acquired from another organism. Reflecting probable gene transfer between the two partners, five genes in this cluster have very high sequence identities with homologs in the genome of " $\mathrm{Ca}$. S. mobilis", three of which are found in CB_GI-1 (Figure S2A in Additional file 1). Because of the very low $\mathrm{G}+\mathrm{C} \mathrm{mol} \%$, these genes are probably not natively found in either Chl. chlorochromatii or "Ca. S. mobilis", and they may have been acquired horizontally by one of the partners and subsequently transferred to the other. Most of the genes in EP_GI-2 and CB_GI-1 are probably involved in cell envelope

Table 1 Properties of genomic islands in Chl. chlorochromatii and "Ca. S. mobilis"

\begin{tabular}{lccll}
\hline Genomic islands & Size $(\mathbf{k b})$ & Number of genes & Transposase/integrase & Putative gene function \\
\hline EP_Gl-1 & 175 & 3 & No & Cell adhesion \\
EP_Gl-2 & 34 & 36 & Yes & Cell envelope biogenesis \\
EP_Gl-3 & 36 & 8 & No & Cell adhesion \\
EP_Gl-4 & 49 & 4 & Yes & Cell adhesion \\
CB_Gl-1 & 12 & 10 & No & Cell envelope biogenesis \\
CB_Gl-2 & 37 & 4 & No & Cell adhesion \\
CB_Gl-3 & 11 & 9 & Yes & Cell envelope biogenesis \\
CB_Gl-4 & 48 & 45 & No & CRISPR-associated and hypothetical proteins \\
CB_Gl-5 & 17 & 33 & Yes & Chemotaxis and regulation \\
CB_Gl-6 & 44 & 15 & No & Poorly defined genes \\
CB_Gl-7 & 22 & 27 & Yes & Cell envelope biosynthesis \\
CB_Gl-8 & 31 & & Poorly defined genes \\
\hline
\end{tabular}


biosynthesis. These results suggest that these two GIs potentially contain genes essential for establishing close cell-to-cell contact and possibly involved in synthesizing symbiosis-specific structures within the consortium.

\section{Metabolism and metabolic coupling}

Genome analyses suggest that "Ca. S. mobilis" has limited metabolic capabilities. Firstly, "Ca. S. mobilis" has no pathways for autotrophic $\mathrm{CO}_{2}$ fixation, and thus it is a heterotroph that relies on exogenous carbon sources. Secondly, it has very limited pathways for energy production. It lacks recognizable genes for anaerobic respiration with nitrate or sulfate as electron acceptors or for oxidation of inorganic electron donors, except for sulfide:quinone oxidoreductase (SqrA; Cenrod_0552). Thus, "Ca. S. mobilis" presumably depends on aerobic respiration or fermentation to produce ATP (but see discussion of interspecies electron transfer below). Compared to its free-living close relatives, " $\mathrm{Ca}$. S. mobilis" apparently lost genes for electron transfer proteins such as cytochrome $c$ :ubiquinol oxidoreductase, cytochrome $c$ oxidase, and most soluble electron carriers (Table S2 in Additional file 2). However, it has retained a complete set of genes for type-1 NADH dehydrogenase and succinate dehydrogenase (Figure 4). The " $\mathrm{Ca}$. S. mobilis" genome includes a single terminal oxidase, a cytochrome $b d$-type quinol oxidase, which might allow respiration to occur under the very low $\mathrm{O}_{2}$ concentrations (approximately $2.9 \mu \mathrm{M}$ ) found in situ [34].

The pairing of an oxygen-sensitive, strict anaerobe and a microaerophile that requires oxygen for some functions is highly unusual. Like other GSB, the epibiont has genes for enzymes involved in protection from reactive oxygen species [35]. Enzymes to protect the cytoplasm of " $\mathrm{Ca}$. S. mobilis" from reactive oxygen species include catalase (Cenrod_0449), Fe-Mn superoxide dismutase (Cenrod_ 1509), alkyl hydroperoxide reductase (Cenrod_0223), and peroxiredoxin (Cenrod_0224, Cenrod_0777, and Cenrod_ 2189) $[35,36]$. The expression of some or all of these oxidative stress proteins could be under the control of an OxyR-like, LysR-family transcription factor (Cenrod_2620).

Only two $c$-type cytochromes are encoded by the " $\mathrm{Ca}$. $\mathrm{S}$. mobilis" genome. One of these is a small, soluble cytochrome $c_{551} / c_{552}$ (Cenrod_0340), and the other is a periplasmic, diheme cytochrome $c$ peroxidase (Cenrod_ 1795). Although the latter might play a role in protecting the periplasm and cells from the toxic effects of hydrogen peroxide, recent studies in Shewanella oneidensis suggest that hydrogen peroxide can also serve as an alternative terminal electron acceptor for dissimilatory energy production [36,37]. In S. oneidensis, the electrons for reduction of hydrogen peroxide to water are derived from the quinone pool [37]. In "Ca. S. mobilis" a membraneassociated cytochrome $b$ (Cenrod_1223) might deliver electrons from menaquinol to cytochrome $c_{551} / c_{552}$, which would serve as the reductant for hydrogen peroxide catalyzed by cytochrome $c$ peroxidase.

The "Ca. S. mobilis" genome encodes genes for the enzymes of glycolysis, the TCA cycle, and the oxidative pentose phosphate pathway (Figure 4). The absence of lactate dehydrogenase, pyruvate decarboxylase, and pyruvateformate lyase limits fermentation possibilities involving pyruvate. However, the presence of pyruvate dehydrogenase (Cenrod_2157 and Cenrod_2158), pyruvate:ferredoxin oxidoreductase (Cenrod_0415, Cenrod_0416, and Cenrod_0417), phosphate acetyltransferase (Cenrod_0908), and acetate kinase (Cenrod_0907) suggests that "Ca. S. mobilis" can extend the glycolytic pathway beyond pyruvate to acetate, while producing additional ATP by substratelevel phosphorylation. As noted above, under microoxic conditions, respiration could occur by transferring electrons from NADH or menaquinol to oxygen or hydrogen peroxide. The resulting proton-motive force could also be used for ATP synthesis by the $\mathrm{F}_{0} \mathrm{~F}_{1}$-type ATP synthase (Cenrod_1756 to 1763).

Under strictly anoxic conditions, protons might be the only available electron acceptor other than $\mathrm{CO}_{2}$ (however, see discussion of interspecies electron transfer below). "Ca. S. mobilis" encodes two different hydrogenases: a bi-directional group 3d NiFe hydrogenase (Cenrod_0973 and Cenrod_0974) with an associated diaphorase complex (Cenrod_0975 and Cenrod_0976) and a group 3c Mvh hydrogenase (Cenrod_2144, Cenrod_2145, and Cenrod_ 2148 ) with an associated heterodisulfide reductase (Cenrod_2147). The diaphorase moiety of the group 3d NiFe hydrogenase should enable the reversible coupling of proton reduction with NADH oxidation [38,39]. During fermentative metabolism, this enzyme could function to reoxidize NADH and reduce protons, but it could alternatively serve as an uptake hydrogenase to oxidize $\mathrm{H}_{2}$ produced by the epibionts when they are fixing nitrogen (no uptake hydrogenase is present in the epibiont genome). In methanogens, the Mvh hydrogenase (MvhADG)-heterodisulfide reductase ( $\mathrm{HdrABC}$ ) complex is proposed to couple the exergonic reduction of heterodisulfide CoM-S$\mathrm{S}$-CoB to coenzyme $\mathrm{M}(\mathrm{CoM})$ and coenzyme $\mathrm{B}(\mathrm{CoB})$ with the energonic reduction of ferredoxin through $\mathrm{H}_{2}$-based electron bifurcation [40-42]. However, the "Ca. S. mobilis" genome does not encode homologs of $\mathrm{HdrB}$ and $\mathrm{HdrC}$, which form the site of disulfide reduction. This feature, coupled with the absence of evidence for the utilization of $\mathrm{CoM}$ and $\mathrm{CoB}$ by this taxon, suggests that this enzyme complex has another function. HdrA binds FAD and is thought to be the site of ferredoxin binding. An intriguing possibility is that this enzyme couples the oxidation of $\mathrm{NADH}$ (approximately $-280 \mathrm{mV}$ ) and ferredoxin oxidation (approximately $-500 \mathrm{mV}$ ) to the reduction of protons. Supporting this possibility, this HdrA subunit (Cenrod_2147) has a NADH binding domain that is not observed in the 


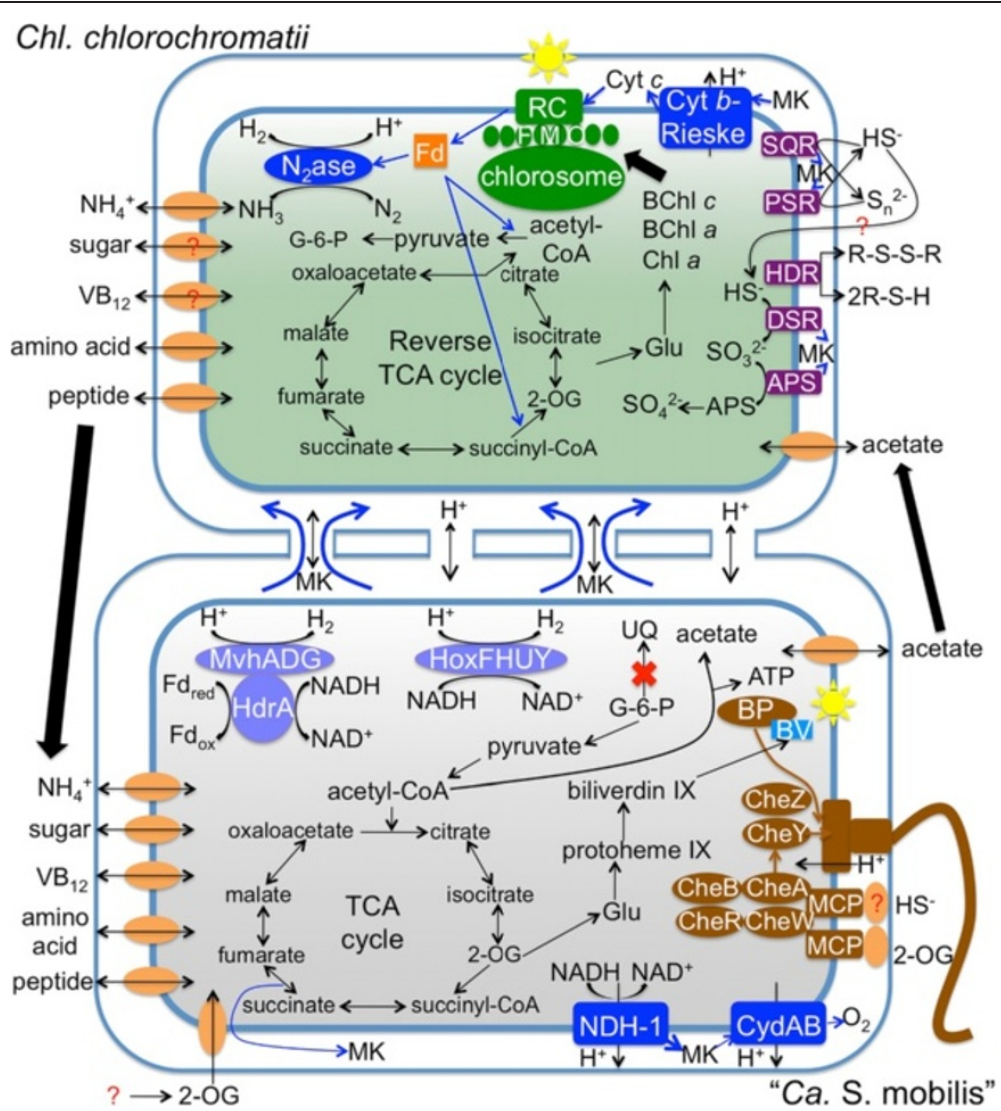

Figure 4 Cellular overview of central metabolism of Chl. chlorochromatii and "Ca. S. mobilis". Only selected pathways and functions are shown to focus on metabolic coupling, chemotaxis and phototaxis. Blue arrows mark the flow of electrons. Question marks denote unidentified proteins or protein complexes. Abbreviations: 2-OG, 2-oxoglutarate; APS, adenosine 5'-phosphosulfate reductase; Bph, bacteriophytochrome; BV, biliverdin; cyt, cytochrome; DSR, dissimilatory sulfite reductase; FMO, Fenna-Matthews-Olson protein; HDR, heterodisulfide reductase; MK, menaquinone; $\mathrm{NDH}-1$, type $1 \mathrm{NADH}$ dehydrogenase; PSR, polysulfide reductase; $\mathrm{Q}$, quinone; RC, photosynthetic reaction center; SQR, sulfide quinone reductase; UQ, ubiquinone; $\mathrm{VB}_{12}$, vitamin $\mathrm{B}_{12}$.

HdrA subunits of heterodisulfide reductases of methanogens. This might ensure that oxidized pyridine nucleotides are available even when other terminal electron acceptors are not.

Chl. chlorochromatii fixes $\mathrm{CO}_{2}$ by the reverse TCA cycle, has a complete set of nif genes, and can thus fix $\mathrm{N}_{2}$ (Figure 4). It excretes large amounts of sugars (mainly glucose) and amino acids (mainly glutamate and aspartate) into the growth medium when grown axenically [43]. In contrast, " $\mathrm{Ca}$. S. mobilis" can neither fix $\mathrm{N}_{2}$ nor assimilate nitrate or nitrite, but it has an ammonia permease (Cenrod_1218) and several sugar and amino acid transporters (Figure 4). It therefore seems likely that sugars and amino acids are transferred from the photoautotrophic epibionts to heterotrophic " $\mathrm{Ca}$. S. mobilis".

2-Oxoglutarate stimulates the growth of "Chlorochromatium aggregatum" [13], and another phototrophic consortium, "Pelochromatium roseum", incorporated 2oxoglutarate in situ [44]. However, 2-oxoglutarate had no effect on the growth of Chl. chlorochromatii [14], suggesting that only " $\mathrm{Ca}$. S. mobilis" assimilates 2-oxoglutarate. Consistent with this idea, the " $\mathrm{Ca}$. S. mobilis" genome encodes one TRAP-type dicarboxylate transporter (Cenrod_1182, Cenrod_2378 and Cenrod_2379). Growth of Chl. chlorochromatii is stimulated by photo-assimilation of acetate [14], which is probably produced from pyruvate by oxidation of sugars or 2-oxoglutarate by " $\mathrm{C} a$. S. mobilis" (see above). These types of metabolite exchange would be mutually beneficial.

"Ca. S. mobilis" probably takes up amino acids released by Chl. chlorochromatii, and two $\mathrm{ABC}$ transporters for 'branched-chain' amino acids (Cenrod_0106 to 0109; Cenrod_2184, Cenrod_2264, Cenrod_2266, and Cenrod_ 2267), as well as other amino acid transporters, are encoded in its genome. Nevertheless, it has not generally abandoned its ability to synthesize amino acids but has streamlined some pathways (Figure 3). For example, "Ca. S. mobilis" cannot perform assimilatory sulfate reduction, but can synthesize cysteine and methionine from sulfide. Instead of using two enzymes, a single 
protein (Cenrod_2045) similar to aminotransferases AspC and TyrB probably performs both activities. 3-Phosphoglycerate dehydrogenase (SerA) appears to be missing, but it is probably premature to conclude that " $\mathrm{Ca}$. S. mobilis" cannot synthesize serine [45]. "Ca. S. mobilis" also probably depends on the epibiont for essential cofactors. " $\mathrm{Ca}$. S. mobilis" has a heterodimeric, MetH-type, cobalamindependent methionine synthase (Cenrod_2368 and Cenrod_2596) but lacks the genes for cobalamin synthesis. However, it has a putative cobalamin transport system, and this suggests that it obtains vitamin $B_{12}$ from the epibiont, which has all genes required for cobalamin synthesis. "Ca. S. mobilis" apparently obtains menaquinone from Chl. chlorochromatii as well (see below). In summary, as in many other symbiotic systems [46], metabolic dependence - mainly of "Ca. S. mobilis" on Chl. chlorochromatii is apparently an important component of the relationship between these two partners (Figure 4).

\section{Chemotaxis, phototaxis, and signal transduction}

Metabolic coupling is obviously critical for the survival of "Ca. S. mobilis"; however, Chl. chlorochromatii is a photolithoautotroph and does not appear to gain much from such coupling. On the other hand, the motility of the consortium provides a huge advantage to the epibiont over free-living relatives. Swimming motility has not been reported for any GSB, and planktonic GSB with gas vesicles can only reposition themselves slowly [47]. Flagella-powered taxis towards sulfide and away from darkness towards light - which are the main energy and electron sources of GSB - would allow consortia to adjust more quickly to fluctuating light and oxygen conditions during the diel cycle in their natural habitats [34]. Diel vertical migration behavior is highly advantageous for the flagellated purple sulfur bacterium Chromatium minus [48], and directed motility is generally regarded as one of the major advantages that allow phototrophic consortia to outcompete free-living GSB [49].

Microscopic analyses have shown that " $\mathrm{Ca}$. S. mobilis" cells possess a single polar flagellum that confers motility to the consortia [34]. Because two of the strongest attractants, light and sulfide, provide no apparent direct benefit to " $\mathrm{Ca}$. S. mobilis", it had been proposed that these attractants were sensed by Chl. chlorochromatii, and that a signal was then transmitted to "Ca. S. mobilis" [13]. The genomic data suggest instead that the genome of the central rod contains the dedicated sensory proteins of the consortium, with a complex photosensory apparatus having similarity to those of cyanobacteria and purple photosynthetic bacteria. In the cyanobacterium Synechocystis sp. PCC 6803, multiple photoreceptors have been implicated in regulating phototaxis, with the domain structure of these sensors implicating multiple signaling pathways. PixD is a member of the blue-light-sensor-using-flavin (BLUF) family with no obvious signaling domains, but it is nevertheless able to interact with a response regulator (REC) protein, PixE [50]. Three members of the phytochrome superfamily are also known to function in determining Synechocystis sp. PCC 6803's responses to blue light [51-55]. One of these proteins, SyPixJ, possesses a carboxy-terminal methylaccepting-chemotaxis-protein (MCP in Figure 5) domain that is also found in chemotactic signaling proteins. Another, UirS or PixA, has a bipartite histidine kinase domain (H/ATP), while the third protein, Cph2, can function as a sensor for both red and blue light and contains GGDEF and EAL domains associated with metabolism of the bacterial second messenger molecule cyclic-di-GMP. Reported phototactic responses to red light in Synechocystis sp. PCC 6803 [56] have not been unambiguously assigned to a given photosensor, but this organism possesses additional histidine kinases in the phytochrome superfamily that exhibit the requisite spectral response [57,58]. Bacteriophytochrome members of this superfamily are also responsible for responses to red and far-red light in the anoxygenic photosynthetic bacterium Rhodopseudomonas palustris [59].

Members of the phytochrome superfamily are thus likely candidate sensors for red-light phototaxis in consortia. Such proteins require linear tetrapyrrole (bilin) chromophores synthesized from heme for photosensory function; in particular, bacteriophytochromes incorporate biliverdin (BV) [60-62]. BV is synthesized from heme by heme oxygenase [63]. Although Chl. chlorochromatii completely lacks genes encoding known photosensors, the " $\mathrm{Ca}$. S. mobilis" genome encodes four bacteriophytochromes (Cenrod_1152, Cenrod_1743, Cenrod_2116, and Cenrod_2641) and heme oxygenase (Cenrod_2642) (Figure 5A). The bacteriophytochrome genes encode the conserved PAS-GAFPHY photosensory region required for photoperception by phytochromes, but they exhibit diverse domain architectures that implicate signaling pathways similar to those reported for Synechocystis sp. PCC 6803 (Figure 5A). There are two histidine kinases, one of which also contains a REC domain. Another bacteriophytochrome has GGDEF, EAL, and MCP domains. The fourth protein, Cenrod_2641, lacks apparent output domains, like PixD from Synechocystis sp. PCC 6803. Cenrod_2641 is encoded in an apparent operon with the sole heme oxygenase gene (Cenrod_2642) found in the "Ca. S. mobilis" genome. The "Ca. S. mobilis" genome thus strongly implicates bacteriophytochromes encoded by the central rod as sensors for phototaxis, with multiple signaling pathways responding to red/far-red light. We expanded on these results by confirming that one of the putative photosensory proteins (Cenrod_2641) encoded by the "Ca. S. mobilis" genome, as well as its cognate heme oxygenase (Cenrod_2642), are functional.

We heterologously expressed Cenrod_2641 in Escherichia coli strains that allowed the co-expression of BV or two 

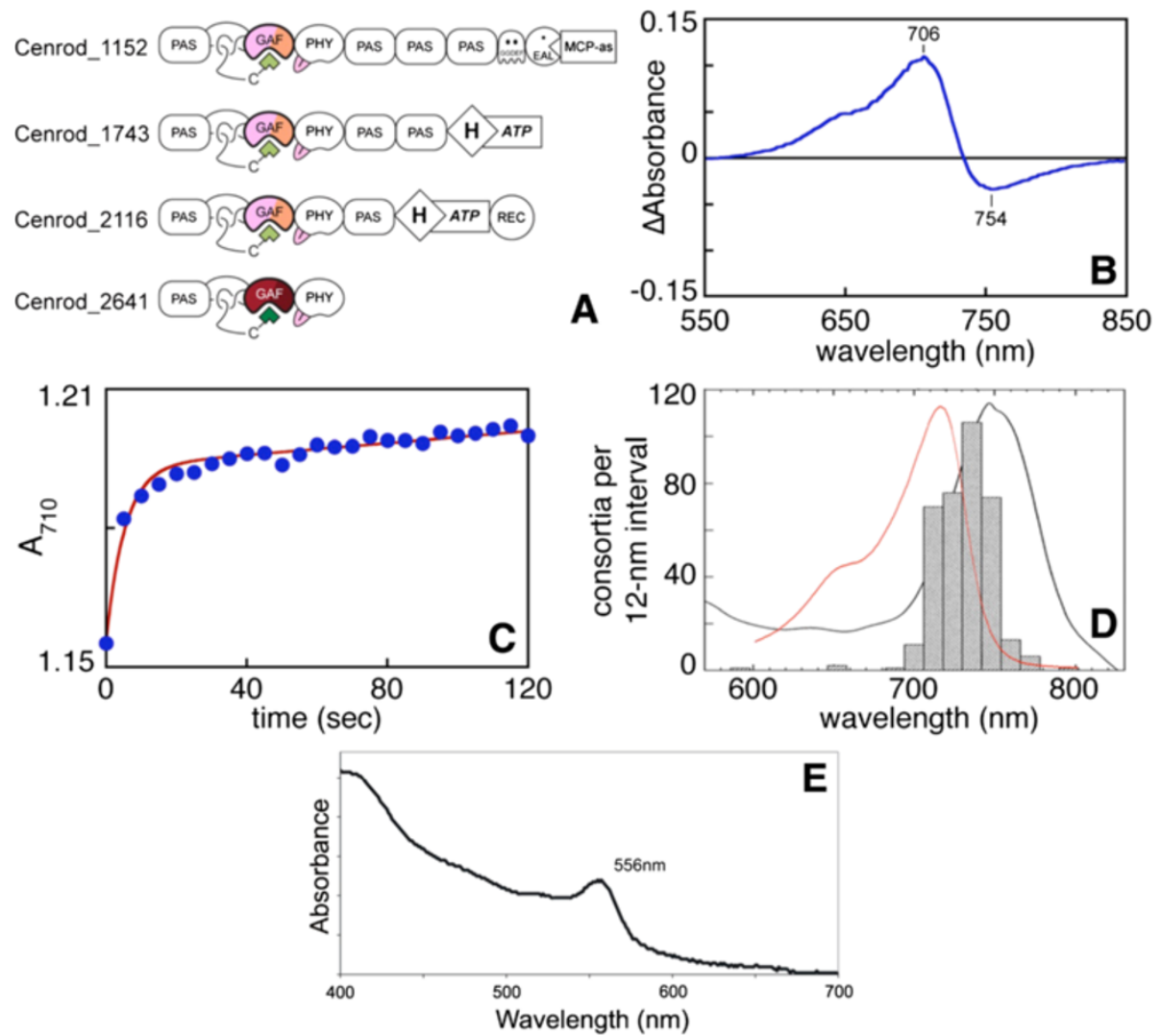

Figure 5 Photosensors of "Ca. S. mobilis". (A) Domain structures of the four bacteriophytochromes encoded in the genome of "Ca. S. mobilis", The experimentally verified red/far-red photocycle and BV chromophore of Cenrod_2641 are indicated by the darker colors; hypothetical photocycles are in faded colors. (B) Red/far-red photocycle of Cenrod_2641. The gene corresponding to Cenrod_2641 was co-expressed with heme oxygenase, which produces biliverdin (BV) from heme when expressed in E. coli. Purified Cenrod_2641 was characterized by absorbance spectroscopy before and after illumination with $700 \pm 20 \mathrm{~nm}$ light. The (Before - After) difference spectrum is shown, with peak wavelengths indicated. (C) Dark reversion of the $750 \mathrm{~nm}$ photoproduct was characterized. Cenrod_2641 was held at photoequilibrium under $700 \mathrm{~nm}$ illumination. Illumination was then discontinued, and absorbance at $710 \mathrm{~nm}$ was monitored as a function of time. Data were biphasic, with the second phase only poorly resolved due to low signal-to-noise. We therefore fit the data to a single exponential with a linear second phase (equivalent to burst kinetics), deriving a rate constant of $0.2 \mathrm{~s}^{-1}$ for the fast initial phase. (D) Comparison of the dark-adapted absorption spectrum of Cenrod_2641 (red curve, arbitrary scale) to the absorption spectrum of intact consortia (black curve, arbitrary scale) and to the integrated number of accumulated consortia per $12 \mathrm{~nm}$ interval (bars, the scotophobotactic response of the consortia) (data from [13]). (E). Absorption spectrum of recombinant CpcA-PEB produced in Escherichia coli. BV, the precursor of phycoerythrobilin (PEB), was produced by Cenrod_2641 (heme oxygenase) and converted to PEB when cells were grown under oxic conditions. No red-colored/gold-fluorescent CPCA-PEB was produced under anoxic conditions, showing that the heme oxygenase encoded by Cenrod_2642 requires oxygen as a co-substrate for heme cleavage.

other linear tetrapyrroles, phycocyanobilin and phytochromobilin [64]. Recombinant bacteriophytochromes produced in these three strains were purified and characterized by absorbance spectroscopy. All three samples had similar absorption spectra with maximal absorption at approximately $710 \mathrm{~nm}$, which suggested that only biliverdin was efficiently incorporated into the protein [65]. Similar to other phytochromes [66,67], Cenrod_2641 photoswitched between a thermally stable dark state and a photoproduct having distinct spectral properties. Upon illumination of the long-wavelength absorption band with $700 \mathrm{~nm}$ light, peak absorbance at $706 \mathrm{~nm}$ decreased with concomitant formation of a photoproduct at $754 \mathrm{~nm}$ (Figure 5B). The photoproduct rapidly converted back to the dark form in the dark (Figure 5C); this process was sufficiently rapid to allow Cenrod_2641 to function as an effective intensity sensor for far-red light $[58,68,69]$. These results showed that Cenrod_2641 has photochemical properties compatible with those of a bona fide photosensor with high affinity for BV.

Figure S3 in Additional file 1 shows a phylogenetic tree that includes bacteriophytochrome sequences from a variety of bacteria, most of which are found in members of the Proteobacteria. The Cenrod_2641 bacteriophytochrome produces a clade with sequences from two members of the genus Methylomicrobium. Although distantly homologous bacteriophytochromes occur in some members of the Comamonadaceae as well as other Betaproteobacteria, 
the bacteriophytochrome encoded by Cenrod_2641 is nested among sequences from Gammaproteobacteria. This result suggests that the gene encoding this bacteriophytochrome (and probably the associated heme oxygenase; data not shown) were acquired by " $\mathrm{Ca}$. S. mobilis" via horizontal gene transfer from a member of the Gammaproteobacteria.

The putative heme oxygenase (Cenrod_2642) was substituted for a functional cyanobacterial heme oxygenase in an $E$. coli strain that can produce a highly fluorescent CpcA protein when $\mathrm{BV}$ is converted into phycoerythrobilin (PEB) by PebS and ligated to CpcA by the phycobiliprotein lyase, $\mathrm{CpcE} / \mathrm{CpcF}$ [64]. As shown in Figure 5E, PEB was produced and ligated to CpcA ( $\lambda_{\max }=$ approximately $556 \mathrm{~nm}$ ) when Cenrod_2642 functionally replaced heme oxygenase in this system under oxic conditions but not under anoxic conditions (data not shown). These results confirm that "Ca. S. mobilis" produces BV for one and up to four bacteriophytochromes, which should allow photoperception in the wavelength range 700 to $760 \mathrm{~nm}$. This wavelength range matches the action spectrum for the scotophobic response of "Chlorochromatium aggregatum" (Figure 5D) [13].

Although light sensing by non-phototrophic bacteria has previously been described in several organisms, in most cases it is associated with protection from reactive oxygen species produced by the interaction of light and photosensitizing molecules [60,70]. The occurrence of scotophobotaxis by a non-phototrophic bacterium - that is, taxis to remain in the light - is extremely rare if not unprecedented. This finding does not completely exclude the original proposal that light is absorbed by chlorosomes and other components of the photosynthetic apparatus of the epibiont cells, which then transmit a signal to " $\mathrm{Ca}$. S. mobilis". The scotophobic response in "Ca. S. mobilis" may have initially been selected and fine-tuned by metabolic signaling (for example, metabolite transfer) from the epibiont to the central rod in the consortium (see below). However, light sensing mediated by bacteriophytochrome (s) is obviously expected to be more direct and to have a more rapid effect on the swimming behavior of " $\mathrm{Ca}$. S. mobilis".

"Ca. S. mobilis" also appears to sense many chemical signals. The "Ca. S. mobilis" genome is enriched in chemotaxis genes, and most of these genes occur in multigene families, including $33 \mathrm{MCP}$ proteins. It is difficult to predict attractants or repellents for non-photosensory MCPs. Some MCP genes are clustered with genes encoding periplasmic solute-binding proteins, which suggests that these MCPs function as signal transducers. Proteins putatively binding phosphate (Cenrod_1484), amino acids (Cenrod_0096) and oligopeptides (Cenrod_0130) were clustered with MCPs, which strongly suggests that cells can probably sense and swim towards (or away from) these compounds. A binding protein for dicarboxylates
(Cenrod_1184) might also interact with MCPs, and this might explain chemotaxis of "Chlorochromatium aggregatum" towards 2-oxoglutarate. It is unknown whether chemotaxis towards sulfide is achieved through a similar mechanism, because proteins for sensing sulfide have not yet been identified. However, given the current lack of understanding about such proteins, sulfide sensing remains a strong possibility for these proteins. Chemotaxis towards compounds excreted by the epibiont, for example, amino acids, could indirectly contribute to taxis towards sulfide, because the excretion of amino acids and other fixed carbon and nitrogen compounds by the epibiont should directly depend on the availability of light and sulfide. However, responses to excreted compounds would probably be much slower than any intracellular mechanism(s) possessed by "Ca. S. mobilis".

Chemical signals sensed by the binding proteins could also have effects on cellular processes other than taxis. Signal transduction between "Ca. S. mobilis" and Chl. chlorochromatii is suggested by at least one previous experiment [44]. Epibiont and central rod cells divide synchronously, and this is presumably coordinated by signaling molecules exchanged between the partners. Such signal transduction might be achieved by mechanisms similar to that of chemotaxis. It is possible that some of the above-mentioned MCP-like proteins participate in regulation of cell cycles as in Myxococcus xanthus [71]. In addition to MCPs, many genes encoding membranebound signal transduction proteins, such as two-component system proteins or proteins containing EAL and/or GGDEF domains, are often clustered with periplasmic solutebinding proteins. Proteins containing these domains have been shown to participate in swarming and cell surface adhesion [72], which is essential for formation of consortia.

\section{Potential interspecies electron transfer}

Besides metabolite exchange and motility, interspecies electron transfer would be extremely advantageous to the consortium in its energy-limited niche. Chl. chlorochromatii relies on having a constant supply of sulfide to provide the electrons it requires for carbon dioxide fixation and growth. Any interaction that increases the availability of sulfide (or electrons) would enhance growth. It was once thought that a sulfur cycle might occur between the two partners. The central bacterium might reduce oxidized sulfur compounds and return the products to the epibiont [73], which would be similar to the sulfur cycling that occurs in a syntrophic co-culture of Chlorobium vibrioforme and Desulfuromonas acetoxidans [74]. This hypothesis was supported by an in situ study that concluded that the increase in biomass by "Pelochromatium roseum" far exceeded the maximum possible $\mathrm{CO}_{2}$ fixation that could be associated with oxidation of sulfide reaching the chemocline from below [34]. Direct photo-assimilation of acetate 
and electrons derived from sulfur cycling between consortia and associated sulfate-reducers were suggested as mechanisms to overcome this shortfall. However, because "Ca. S. mobilis" is a member of Betaproteobacteria, and within the Proteobacteria all known sulfate-reducers are members of the Deltaproteobacteria, a sulfur cycling mechanism seemed unlikely to occur in the consortia. The genomic data are consistent with predictions based on phylogenetic associations. The "Ca. S. mobilis" genome does not contain known genes for the reduction of sulfate or sulfur to sulfide [75].

The genomic data were searched for other possible mechanisms of interspecies electron transfer. However, other than the two NiFe-hydrogenases described above, only one other set of electron transfer-related proteins was identified. The " $\mathrm{Ca}$. S. mobilis" genome encodes six genes (Cenrod_1907 to 1912) that have some sequence similarity to subunits of formate hydrogenlyase ( $\mathrm{Hyf}$ subunits B, C, E, F, G, and I) [76] as well as modules of some other electron transfer complexes, including the Mbx complexes thought to be involved in sulfur reduction [77]. The occurrence of highly similar gene clusters in more than 300 bacteria, including free-living members of the Comamonadaceae that do not live in sulfidic environments, strongly suggests that this complex is not involved in sulfur reduction. Cenrod_1908 exhibits homology with the large subunit of NiFe-hydrogenase but lacks the required L1 and L2 cysteine ligands required to coordinate the NiFe cofactor [78], which implies that this complex is not involved in $\mathrm{H}_{2}$ cycling. This complex possibly plays a role in coupling menaquinone oxidation/ reduction to proton translocation, but the redox partner for this process and its directionality are presently uncertain.

Quinone exchange is a potential mechanism for electron shuttling between the two partners of the consortium. "Ca. S. mobilis" lacks genes for either of the two known pathways for menaquinone biosynthesis [79-81], and it has an incomplete ubiquinone biosynthesis pathway. However, all free-living members of the Comamonadaceae can synthesize ubiquinone, and these organisms universally have two genes, $u b i H / c o q 6$ and $u b i F / c o q 7$, which encode oxygen-dependent enzymes that are missing from the genome of "Ca. S. mobilis" (Figure 6; Table S2 in Additional file 2). Either "Ca. S. mobilis" lacks the ability to synthesize isoprenoid quinones, or it has acquired or evolved unknown genes to replace the activities of these two missing enzymes. The latter seems highly unlikely because only menaquinone- 7 and no ubiquinone was detected in intact consortia and cell fractions enriched in "Ca. S. mobilis" (Figure S3 in Additional file 1).

The genomic data, however, strongly suggest that " $\mathrm{Ca}$. S. mobilis" cells utilize quinones. At least four important electron-transport complexes (type-1 NADH dehydrogenase, succinate dehydrogenase, cytochrome $b d$-type quinol oxidase, and sulfide:quinone reductase) that are encoded in the "Ca. S. mobilis" genome require a quinone substrate. The presence of these genes strongly suggests that quinones are available to the central bacterium; otherwise, these genes should have been partially or completely lost. Extracellular transfer of quinones has previously been described from wild-type Shewanella putrefaciens to a mutant that was unable to synthesize menaquinone [82]. Similarly, respiration can be activated in Group B Streptococcus spp. by menaquinone synthesized by Lactococcus lactis [83]. Finally, exchange of a water-soluble intermediate, 1,4-dihydroxy-2-naphthoic acid, can satisfy the quinone requirement of members of dental plaque [84]. Thus, we hypothesize that menaquinone-7, or a soluble quinone intermediate synthesized by Chl. chlorochromatii, can be transferred to " $\mathrm{Ca}$. S. mobilis".

The availability of quinones for respiration in "Ca. S. mobilis" solves only one of two problems. Consortia are usually cultivated under strictly anoxic conditions in the laboratory and thus should not have any terminal electron acceptor for respiration. Although "Ca. S. mobilis" can probably produce ATP by fermentation of glucose under anoxic conditions as described above, an energetically more favorable solution would involve bidirectional quinone transfer and sharing of the resulting protonmotive force. Quinones transferred to "Ca. S. mobilis" would allow energetically more favorable electron transfer processes to occur in the central bacterium, and electrons returned by quinols to the epibiont could be reused for $\mathrm{CO}_{2}$ fixation. Although this process does not involve sulfide, it produces results similar to sulfur cycling. The exchange of electrons and shared proton-motive force would be beneficial to both symbiotic partners and would additionally allow ATP synthesis in the central rod to be directly coupled to the light reactions of photosynthesis in the epibiont. This might partly explain the phototactic and chemotactic behavior of the central bacterium, and this could additionally explain the substantial loss of genes for energy metabolism from the central bacterium (Figure 3). Fermentation could still provide ATP for the central bacterium under anoxic conditions in the dark.

For either sulfide- or quinone-dependent electron shuttling and shared proton-motive force to occur, symbiosisspecific, specialized cell wall structures would likely be required. The central rod and epibiont cells are joined by numerous 'periplasmic tubules' [17], which are reminiscent of the bacterial nanowires that have recently been found in many organisms, including Geobacter sulfurreducens and Shewanella oneidensis and between organisms in syntrophic co-cultures of Pelotomaculum thermopropionicum and Methanothermobacter thermoautotropicus. Electrically conductive nanowires in these organisms have been proposed to be conduits for extracellular or interspecies 


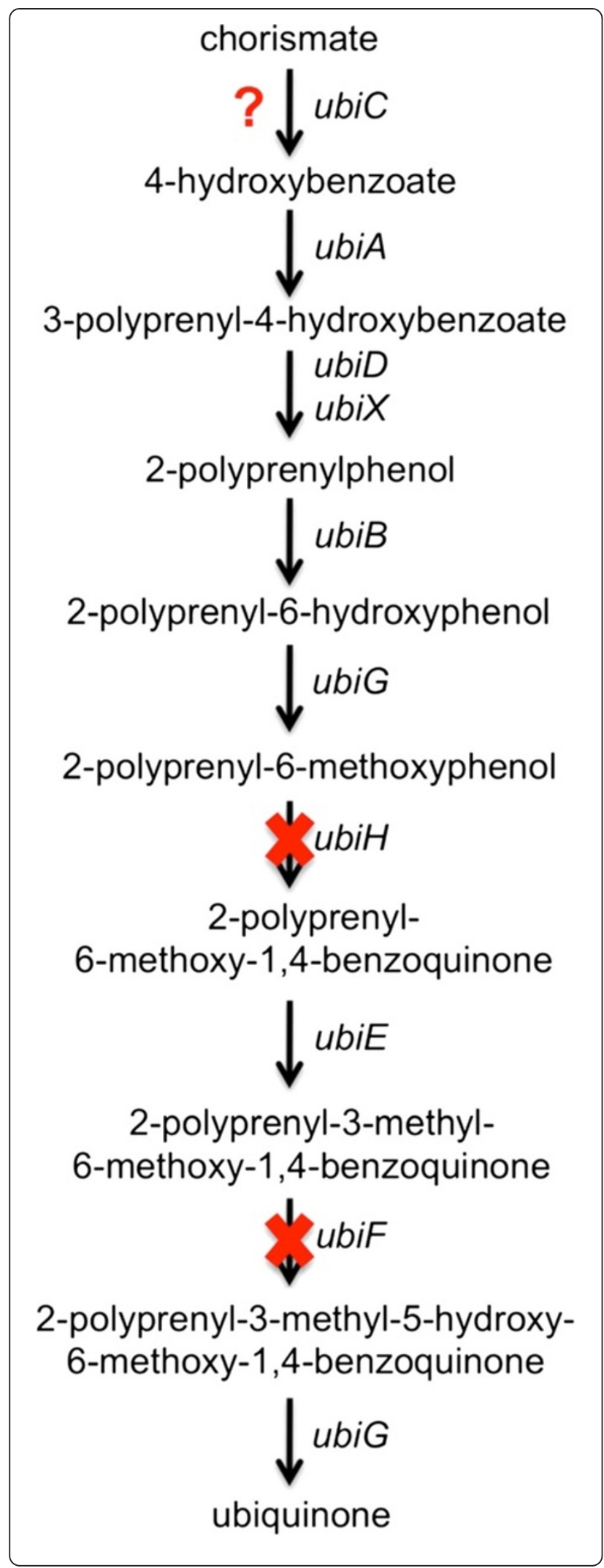

Figure 6 Ubiquinone biosynthesis pathway of "Ca. S. mobilis". This pathway is compared with the ubiquinone biosynthesis pathways found in 15 members of the Comamonadaceae, including the 8 listed in the Figure 2 legend as well as 3 additional Acidovorax spp., 2 additional Comamonas spp., one additional Polaromonas sp. and one additional Variovorax sp. The ubiC gene was identified in only one of the 15 genomes, possibly because of its extremely low sequence similarity and conservation across species. The ubiH/coq6 and $u b i F / c o q 7$ genes are highly conserved and were identified in each of the 15 reference genomes, but these genes were not found in "Ca. S. mobilis".

electron transfer $[85,86]$. The electron carriers in some cases appear to be cytochromes, but other electron carrier molecules could function in organisms devoid of cytochromes [85,87]. The periplasmic tubules of phototrophic consortia could have similar functions, and quinone-like molecules, whether soluble or shuttled by proteins, might facilitate electron exchange between " $\mathrm{Ca}$. S. mobilis" and Chl. chlorochromatii. Periplasmic tubules are larger in diameter than pili and bacterial nanowires, and they connect the outer membranes of the two cell types, thus creating a joint periplasmic space between the epibionts and central bacterium [17]. Periplasmic tubules thus provide a mechanism for sharing proton-motive force generated by the proposed electron shuttle between the two organisms. The potential schemes for interspecies electron transfer hypothesized here will obviously have to be tested experimentally in the future. Nevertheless, they provide an additional perspective for the symbiotic relationship of phototrophic consortia. Electron shuttling and shared protonmotive force would join metabolite exchange and phototaxis/chemotaxis in creating a strong, competitive advantage for consortia over free-living members of the GSB.

\section{Conclusions}

Genomic data for the phototrophic consortium "Chlorochromatium aggregatum" suggest that a very sophisticated symbiotic relationship has evolved between the central bacterium, "Ca. S. mobilis", which apparently is no longer capable of independent growth, and the epibiont, Chl. chlorochromatii, which is still capable of independent growth. We propose that three types of interactions occur between the two partners (Figure 4). Firstly, metabolite exchange, which is common in many other symbiotic organisms, also occurs in this consortium, but the wide variety of exchanged metabolites, including carbon, nitrogen and sulfur sources and vitamins, is uncommon [40]. Secondly and remarkably, "Ca. S. mobilis" can sense light and probably sulfide, which are most directly beneficial to Chl. chlorochromatii. "Ca. S. mobilis" can also sense other nutrients and probably the metabolic status of Chl. chlorochromatii. Figuratively, Chl. chlorochromatii 
cells are the solar panels of this self-perpetuating, solarenergy-powered bacterial machine; "Ca. S. mobilis" not only provides the bus but also the driver and a navigation system. The degree of specialization observed for these two organisms approaches that seen in multicellular organisms. Although phototrophic consortia are composed of two different organisms, studies of these consortia might offer insights into the evolutionary processes that led from single-celled to multicellular organisms. Thirdly, electron cycling mechanisms, particularly those mediated by quinones and potentially shared proton-motive force, could provide important new mechanistic bases for energy exchange in symbiotic relationships. This study provides many novel insights for this specific bacterial symbiosis, but it also reveals benchmarks for understanding other phototrophic consortia, bacterial symbioses in general, and more complex communities and multicellularity.

\section{Materials and methods}

\section{Culture and DNA preparation}

Genomic DNA of the epibiont was extracted from an axenic culture of Chl. chlorochromatii strain CaD3 [14]. The central bacterium has not yet been grown axenically. Consortia were grown under conditions that produced a biofilm on a glass surface, which could be recovered and which reduced contamination from other bacteria in the enrichment culture. The consortia cultures were pelleted and resuspended in $\mathrm{K} 4$ medium lacking $\mathrm{H}_{2} \mathrm{~S}$ and $\mathrm{NaHCO}_{3}$ to an $\mathrm{OD}_{650 \mathrm{~nm}}=4$. To disaggregate the biofilm and consortia into single cells, a cell suspension was incubated in a water bath at $68^{\circ} \mathrm{C}$ for 10 minutes. During the incubation, aggregates were disrupted by passing the culture through a syringe $(0.80 \mathrm{~mm} \times 120 \mathrm{~mm})$ several times. Subsequently, the central bacterial cells were separated from the epibiont by $\mathrm{CsCl}$ equilibrium density centrifugation [18]. The two distinct bands containing cells of the epibiont and central bacterium were removed with a syringe and needle $(0.80 \mathrm{~mm} \times 120 \mathrm{~mm})$ and aliquots $(20 \mu \mathrm{l})$ of cells were removed from each fraction for fluorescent in situ hybridization (FISH) analysis to assess the level of cross-contamination in each fraction [18]. The remaining volume was mixed with sterile double-distilled water, pelleted and rapidly frozen in liquid nitrogen. A fraction highly enriched in " $\mathrm{C}$. S. S. mobilis" was used to extract DNA used for genome sequencing of " $\mathrm{Ca}$. S. mobilis".

\section{Sequencing and assembly}

The genome of Chl. chlorochromatii was sequenced using the whole genome shotgun sequencing approach and the assembly and finishing process have been described elsewhere [16]. The enriched genomic DNA sample from "Ca. S. mobilis" was sequenced using pyrosequencing technology (GS-20 FLX; 454 Life Sciences, Branford, CT,
USA). A total of 1,064,718 sequences, averaging $362 \mathrm{bp}$ per sequence, were generated. Sequences with at least $98 \%$ nucleotide sequence identity to Chl. chlorochromatii, defined by alignment to its genome, were removed before the remaining sequences were assembled using the Newbler program (454 Life Sciences). About 23\% of the total sequences were removed in this filtering process. A different approach, in which Chl. chlorochromatii contigs were removed after all sequences had been assembled, resulted in very similar assemblies. The average read depths of the former assembly, which contained 3,508 contigs, was examined: 121 contigs had read depths averaging approximately $83 \times$, while the remainder had much lower read depths (approximately $4 \times$ to $6 \times$ on average). Because genes associated with these 121 contigs appeared to be closely related to those of Betaproteobacteria, these contigs were tentatively assigned to "Ca. S. mobilis". The other contigs probably arose from other organisms in the enrichment culture. These 121 contigs, which were assembled from 668,485 sequences (63\% of original sequence pool), were used for subsequent assembly and finishing. The original trace files for sequencing the " $\mathrm{Ca}$. $\mathrm{S}$. mobilis" genome have been deposited in the Sequence Read Archive at GenBank under the Biosample accession number SRS500535.

For finishing, a set of sequences that were derived from Sanger sequencing of clone libraries with 3 and $8 \mathrm{~kb}$ inserts and produced from total genomic DNA from "Chlorochromatium aggregatum" by the DOE Joint Genome Institute were used. A total of 9,798 paired-end sequences with at least $95 \%$ nucleotide sequence identity to the 121 initial contigs were extracted and added to the assembly dataset to predict contig arrangements into scaffolds. Based on predictions from these analyses, PCR amplicons were produced and sequenced to close most of the 121 gaps in the scaffolds. PCR amplicons for other gaps were obtained using multiplex PCR, TAIL-PCR or combinatorial PCR [88]. The finishing and polishing process was carried out using the Phred/Phrap/Consed software package [89,90]. The genome of Chl. chlorochromatii was annotated by the Joint Genome Institute and deposited in GenBank (accession number CP000108). The genome of " $\mathrm{Ca}$. S. mobilis" was annotated using a previously described pipeline [91] and has also been deposited in GenBank (accession number CP004885).

\section{Identification of genomic islands}

The genomic islands were first predicted using the program Alien_hunter [92]. A score cutoff of 25 and a size cutoff of $10 \mathrm{~kb}$ were used. Predicted islands were manually inspected to eliminate falsely identified regions such as rRNA and extremely conserved proteins (ribosomal proteins) because of their naturally biased sequence composition. Boundaries of remaining islands were then carefully optimized by 
inspecting BLASTX hits of genes in the islands in the NCBI nr database. Genes near the ends of islands were removed if they were closely related to proteins of related organisms or were added if the opposite was true.

\section{Expression and characterization of bacteriophytochrome}

A putative bacteriophytochrome gene (Cenrod_2641) was amplified by polymerase chain reaction from DNA enriched from the central rod using primers: CRBP1F ( $5^{\prime}-\mathrm{G}$ AGCACCCTCATATGACCGACATGATCCTGATC-3') and CRBP1R (5' ${ }^{\prime}$-TGGTTTGAATTCTCATAGCCAGCG TAGAAGGTT-3'). The resulting product was then digested with NdeI and EcoRI and ligated into similarly digested pBS405v [93]. This construct allowed the expression of the putative bacteriophytochrome with a hexa-His tag. The resulting plasmid was cotransformed into E. coli BL21 (DE3) with plasmid pHO1, which directs the synthesis of biliverdin from heme [64].

A putative heme oxygenase (Cenrod_2642) was PCR amplified from central rod enriched DNA using primers CRHOF (5'-GCTGCACCGCCATATGCGGCAAGCAAG CAAGTTG-3') and CRHOR (5' -ACCAGTGATATCTCA CTGCCCCGCTGCTGCC-3'), digested with NdeI and EcoRV, and cloned into similarly digested pACYC Duet-1 (Novagen, Madison, WI, USA) to create the plasmid pACYC-CRHO. In order to create a plasmid with both Cenrod_2642 and pebS, the plasmid pPebS [93] was digested with BamHI and NotI and the resulting 719 bp fragment containing $p e b S$ was cloned into similarly digested pACYC-CRHO. This new plasmid, pACYC-CRHOpebS, was then co-transformed along with the plasmid pBS414 $\mathrm{v}$ [94] into E. coli BL21 (DE3) cells. This strain was visually assayed for its ability to produce a functional phycoerythrobilin chromophore that could be attached to CpcA as described previously [64]. The E. coli cells were bright red in color when grown under oxic conditions but were uncolored when grown under anoxic conditions. These results showed that the putative heme oxygenase was functional and produced biliverdin when oxygen was present [64].

Absorbance spectroscopy and photochemistry were carried out at $25^{\circ} \mathrm{C}$ using a Cary 50 spectrophotometer and a $75 \mathrm{~W}$ Xe lamp as previously described [95]. Illumination was restricted to $700 \pm 20 \mathrm{~nm}$ or $650 \pm 20 \mathrm{~nm}$ with interference band-pass filters (CVI Melles Griot).

\section{HPLC analyses of quinones}

Quinones were extracted from cells with methanol:acetone (7:2, vol:vol), analyzed by reversed-phase high-performance liquid chromatography as previously described $[96,97]$, and detected by absorption at $270 \mathrm{~nm}$. Reference compounds ubiquinone- 8 and menaquinone- 8 were extracted from E. coli cells grown under oxic or anoxic conditions, respectively, and menaquinone-7 was obtained from
Chlorobaculum tepidum cells [96]. Only menaquinone-7 was detected in extracts prepared from intact consortia and fractions enriched in the central bacterium.

\section{Additional files}

Additional file 1: Figure S1. Scanning electron micrographs (A-E) and epifluorescence $(\mathrm{F}-\mathrm{H})$ photomicrographs of 'Chlorochromatium aggregatum.' Figure S2. Genes in selected genomic islands of Chl. chlorochromatii and "Ca. S. mobilis". Figure S3. Phylogenetic analysis of one bacteriophytochrome gene (Cenrod_2641) and its most similar homologs in the database and those in taxonomically related organisms. Figure S4. Quinone analysis of 'Chlorochromatium aggregatum'.

Additional file 2: Table S1. Genes unique to Chl. chlorochromatii that are not found in other GSB. Table S2. Conserved orthologous Comamonadaceae genes that are missing in the genome of "Ca. S. mobilis". Table S3. Genes unique to "Ca. S. mobilis" that do not have orthologs in 8 other Comamonadaceae genomes. Table S4. Potential horizontal transferred gene pairs of "Ca. S. mobilis" and Chl. chlorochromatii.

\section{Abbreviations}

bp: base pair; BV: biliverdin; Ca: Candidatus; CB_Gl: genomic island in central bacterium "Ca. S. mobilis"; Chl.: Chlorobium; EP_Gl: genomic island in epibiont Chl. chlorochromatii; Gl: genomic island; GSB: green sulfur bacteria; MCP: methyl-accepting chemotaxis protein; ORF: open reading frame; PEB: phycoerythrobilin; TCA: tricarboxylic acid cycle.

\section{Competing interests}

The authors declare that they have no competing interests.

\section{Authors' contributions}

SCS, JO and DAB designed research. ZL, JM, TL, RMA, KV, N-UF, NCR, LPT, SCS, PH, and MR performed research. ZL, TL, N-UF, ESB and DAB analyzed data. ZL, N-UF, NCR, JO and DAB wrote the paper. All authors read and approved the final manuscript.

\section{Acknowledgements}

The authors would like to thank staff of the Joint Genome Institute, and especially Lynne Goodwin, who obtained some early Sanger sequence data later used as scaffolding information for this project. The work conducted by the US Department of Energy Joint Genome Institute is supported by the Office of Science of the US Department of Energy under contract number DE-AC02-05CH11231. The authors also thank Dr Daniel Drell for his support and interest in this project. DAB acknowledges support from the Division of Chemical Sciences, Geosciences, and Biosciences, Office of Basic Energy Sciences of the US Department of Energy (grant DE-FG02-94ER20137) and from the National Science Foundation (MCB-0523100). ESB acknowledges support from the NASA Exobiology and Evolutionary Biology Program (grant NNX13Al11G).

\section{Author details}

${ }^{1}$ Department of Biochemistry and Molecular Biology, The Pennsylvania State University, University Park, PA 16802, USA. ${ }^{2}$ Leibniz-Institut DSMZ-Deutsche Sammlung von Mikroorganismen und Zellkulturen GmbH, Inhoffenstraße 7B, 38124, Braunschweig, Germany. ${ }^{3}$ Section for Marine Biology, Department of Biology, University of Copenhagen, Strandpromenaden 5 3000, Helsingør, Denmark. ${ }^{4}$ Department of Molecular and Cellular Biology, University of California, Davis, CA 95616, USA. ${ }^{5}$ Department of Microbiology, Montana State University, Bozeman, MT 59717, USA. ${ }^{6}$ Helmholtz-Zentrum für Infektionsforschung, 38124 Braunschweig, Germany. ${ }^{7}$ Current address: Department of Biological Sciences, University of Southern California, Los Angeles, CA 90089, USA. ${ }^{8}$ Current address: Algal Genomics Research Group, Institute of Hydrobiology, Chinese Academy of Sciences, Wuhan, Hubei 430072, China. ${ }^{9}$ Current address: Department of Biology, Chaminade University, Honolulu, HI 96816, USA. 
Received: 4 June 2013 Accepted: 22 November 2013

Published: 22 November 2013

\section{References}

1. Oldroyd GE, Murray JD, Poole PS, Downie JA: The rules of engagement in the legume-rhizobium symbiosis. Annu Rev Genet 2011, 45:119-144.

2. Dubilier N, Bergin C, Lott C: Symbiotic diversity in marine animals: the art of harnessing chemosynthesis. Nat Rev Microbiol 2008, 6:725-740.

3. Moissl-Eichinger C, Huber H: Archaeal symbionts and parasites. Curr Opin Microbiol 2011, 14:364-370.

4. Overmann J: Phototrophic consortia: a tight cooperation between non-related eubacteria. In Symbiosis: Mechanisms and Model Systems. Edited by Seckbach J. Dordrecht: Kluwer; 2001:239-255.

5. Mclnerney MJ, Sieber JR, Gunsalus RP: Syntrophy in anaerobic global carbon cycles. Curr Opin Biothechnol 2009, 20:623-632.

6. Klatt CG, Liu Z, Ludwig M, Kühl M, Jensen SI, Bryant DA, Ward DM: Community ecology of hot spring cyanobacterial mats: predominant populations and their functional potential. ISME J 2011, 5:1262-1278.

7. Knittel K, Boetius A: Anaerobic oxidation of methane: progress with an unknown process. Annu Rev Microbiol 2009, 63:311-334.

8. Schink B: Syntrophism among prokaryotes. In The Prokaryotes. Edited by Balows A, Trüper HG, Dworkin M, Harder W, Schleifer K-H. Berlin: Springer; 1991:276-299.

9. Lauterborn R: Zur Kenntnis der sapropelischen Flora. Allg Bot Z 1906, 12:196-197.

10. Overmann J, Schubert K: Phototrophic consortia: model systems for symbiotic interrelations between prokaryotes. Arch Microbiol 2002, 177:201-208.

11. Overmann J: Symbiosis between non-related bacteria in phototrophic consortia. In Progress in Molecular and Subcellular Biology. Edited by Overmann J. Berlin: Springer; 2006:21-37.

12. Overmann J: The phototrophic consortium "Chlorochromatium aggregatum"-a model for bacterial heterologous multicellularity. In Recent Advances in Phototrophic Prokaryotes, ed Hallenbeck PC. Berlin: Springer; 2010:15-29.

13. Fröstl JM, Overmann J: Physiology and tactic response of the phototrophic consortium 'Chlorochromatium aggregatum'. Arch Microbiol 1998, 169:129-135.

14. Vogl K, Glaeser J, Pfannes KR, Wanner G, Overmann J: Chlorobium chlorochromatii sp. nov., a symbiotic green sulfur bacterium isolated from the phototrophic consortium 'Chlorochromatium aggregatum'. Arch Microbiol 2006, 185:363-382.

15. Vogl K, Wenter R, Dressen M, Schlickenrieder M, Plöscher M, Eichacker L, Overmann J: Identification and analysis of four candidate symbiosis genes from 'Chlorochromatium aggregatum', a highly developed bacterial symbiosis. Environ Microbiol 2008, 10:2842-2856.

16. Wenter R, Hütz K, Dibbern D, Li T, Reisinger V, Plöscher M, Eichacker L, Eddie B, Hanson T, Bryant DA, Overmann J: Expression-based identification of genetic determinants of the bacterial symbiosis 'Chlorochromatium aggregatum'. Environ Microbiol 2010, 12:2259-2276.

17. Wanner G, Vogl K, Overmann J: Ultrastructural characterization of the prokaryotic symbiosis in 'Chlorochromatium aggregatum'. J Bacteriol 2008, 190:3721-3730.

18. Kanzler BE, Pfannes KR, Vogl K, Overmann J: Molecular characterization of the nonphotosynthetic partner bacterium in the consortium 'Chlorochromatium aggregatum'. Appl Environ Microbiol 2005, 71:7434-7441.

19. Fröstl J, Overmann J: Phylogenetic affiliation of the bacteria that constitute phototrophic consortia. Arch Microbio/ 2000, 174:50-58.

20. Glaeser J, Overmann J: Biogeography, evolution, and diversity of epibionts in phototrophic consortia. Appl Environ Microbiol 2004, 70:4821-4830

21. Pfannes KR, Vogl K, Overmann J: Heterotrophic symbionts of phototrophic consortia: members of a novel diverse cluster of Betaproteobacteria characterized by a tandem rrn operon structure. Environ Microbio/ 2007, 9:2782-2794.

22. Bryant DA, Liu Z, Li T, Zhao F, Garcia Costas AM, Klatt CG, Ward DM, Frigaard $\mathrm{N}-\mathrm{U}$, Overmann J: Comparative and functional genomics of anoxygenic green bacteria from the taxa Chlorobi, Chloroflexi, and Acidobacteria. In Advances in Photosynthesis and Respiration. Volume 33, Functional Genomics and Evolution of Photosynthetic Systems. Edited by Burnap RL, Vermaas W. Dordrecht: Springer; 2012:47-102.
23. Frigaard $\mathrm{N}-\mathrm{U}$, Bryant DA: Seeing green bacteria in a new light: genomics-enabled studies of the photosynthetic apparatus in green sulfur bacteria and filamentous anoxygenic phototrophic bacteria. Arch Microbiol 2004, 182:265-276.

24. Frigaard $\mathrm{N}-\mathrm{U}$, Bryant DA: Chlorosomes: antenna organelles in green photosynthetic bacteria. In Microbiology Monographs. Volume 2, Complex Intracellular Structures in Prokaryotes. Edited by Shively JM. Berlin: Springer; 2006:79-114.

25. Bryant DA, Frigaard N-U: Prokaryotic photosynthesis and phototrophy illuminated. Trends Microbiol 2006, 14:488-496.

26. Nikoh N, Hosokawa T, Oshima K, Hattori M, Fukatsu T: Reductive evolution of bacterial genome in insect gut environment. Genome Biol Evol 2011, 3:702-714.

27. McCutcheon JP, Moran NA: Extreme genome reduction in symbiotic bacteria. Nat Rev Microbiol 2011, 10:13-26.

28. Integrated Microbial Genomes. http://img.jgi.doe.gov/cgi-bin/w/main.cgi

29. Satchell KJ: Structure and function of MARTX toxins and other large repetitive RTX proteins. Annu Rev Microbiol 2011, 65:71-90.

30. Opitz CA, Kulke M, Leake MC, Neagoe C, Hinssen H, Hajjar RJ, Linke WA: Damped elastic recoil of the titin spring in myofibrils of human myocardium. Proc Natl Acad Sci U S A 2003, 100:12688-12693.

31. Madigan MT, Jung DO: An overview of purple bacteria: systematics, physiology, and habitats. In Advances in Photosynthesis and Respiration. Volume 28, The Purple Phototrophic Bacteria. Edited by Hunter CN, Daldal F, Thurnauer MC, Beatty JT. Dordrecht: Springer; 2009:1-14.

32. Gest H: Phototaxis and other sensory phenomena in purple photosynthetic bacteria. FEMS Microbiol Rev 1995, 16:287-294.

33. Thar R, Kühl M: Motility of Marichromatium gracile in response to light, oxygen, and sulfide. Appl Environ Micribiol 2001, 67:5410-5419.

34. Overmann J, Tuschak C, Fröstl JM, Sass H: The ecological niche of the consortium "Pelochromatium roseum". Arch Microbiol 1998, 169:120-128.

35. Li H, Jubilerer S, Garcia Costas AM, Bryant DA: Multiple antioxidant proteins protect Chlorobaculum tepidum against oxygen and reactive oxygen species. Arch Microbio/ 2009, 191:853-867.

36. Mishra S, Imlay J: Why do bacteria use so many enzymes to scavenge hydrogen peroxide? Arch Biochem Biophys 2012, 525:145-160.

37. Schütz B, Seidel J, Sturm G, Einsle O, Gescher J: Investigation of the electron transport chain to and the catalytic activity of the diheme cytochrome c peroxidase CcpA of Shewanella oneidensis. Appl Environ Microbiol 2011, 77:6172-6180

38. Rákhely G, Kovács ÁT, Maróti G, Fodor BD, Csanádi G, Latinovics D, Kovács $\mathrm{KL}$ : Cyanobacterial-type, heteropentameric, $\mathrm{NAD}^{+}$-reducing $\mathrm{NiFe}$ hydrogenase in the purple sulfur photosynthetic bacterium Thiocapsa roseopersicina. Appl Environ Microbiol 2004, 70:722-728.

39. Grzeszik C, Lübbers M, Reh M, Schlegel HG: Genes encoding the NAD-reducing hydrogenase of Rhodococcus opacus MR11. Microbiology 1997, 143:1271-1286.

40. Thauer RK, Kaster A-K, Seedorf H, Buckel W, Hedderich R: Methanogenic archaea: ecologically relevant differences in energy conservation. Nat Rev Microbiol 2008, 6:579-591.

41. Kaster A-K, Moll J, Parey K, Thauer RK: Coupling of ferredoxin and heterosulfide reduction via electron bifurcation in hydrogenotrophic methanogenic archaea. Proc Natl Acad Sci U S A 2011, 108:2981-2986.

42. Buckel W, Thauer RK: Energy conservation via electron bifurcating ferredoxin reduction and proton/ $\mathrm{Na}(+)$ translocating ferredoxin oxidation. Biochim Biophys Acta 1827, 2013:94-113.

43. Pfannes KR: Characterization of the symbiotic bacterial partners in phototrophic consortia. PhD thesis. Ludwig-Maximilians Universität München: Bereich Mikrobiologie, Department Biologie I; 2007

44. Glaeser J, Overmann J: The significance of organic carbon compounds for in situ metabolism and chemotaxis of phototrophic consortia. Environ Microbiol 2003, 5:1053-1063.

45. Eisen JA, Nelson KE, Paulsen IT, Heidelberg JF, Wu M, Dodson RJ, Deboy R, Gwinn ML, Nelson WC, Haft DH, Hickey EK, Peterson JD, Durkin AS, Kolonay $J$, Yang F, Holt I, Umayam LA, Mason T, Brenner M, Shea TP, Parksey D, Nierman WC, Feldblyum TV, Hansen CL, Craven MB, Radune D, Vamathevan J, Khouri H, White O, Gruber TM, Ketchum KA, Venter JC, Tettelin H, Bryant DA, Fraser CM: The complete genome sequence of Chlorobium tepidum TLS, a photosynthetic, anaerobic, green-sulfur bacterium. Proc Natl Acad Sci U S A 2002, 99:9509-9514

46. Moran NA: Symbiosis. Curr Biol 2006, 16:R866-871. 
47. Overmann J, Lehmann S, Pfenning N: Gas vesicle formation and buoyancy regulation in Pelodictyon phaeoclathratiforme (Green sulfur bacteria). Arch Microbiol 1991, 157:29-37.

48. Pedrós-Alió C, Sala M: Microdistribution and diel vertical migration of flagellated vs. gas-vacuolate purple sulfur bacteria in a stratified water body. Limnol Oceanogr 1990, 35:1637-1644.

49. Müller J, Overmann J: Close interspecies interactions between prokaryotes from sulfureous environments. Front Microbio 2011, 2:146.

50. Okajima KS, Yoshihara S, Fukushima Y, Geng X, Katayama M, Higashi S, Watanabe M, Sato S, Tabata S, Shibata Y, Itoh S, Ikeuchi M: Biochemical and functional characterization of BLUF-type flavin-binding proteins of two species of cyanobacteria. J Biochem 2005, 137:741-750.

51. Yoshihara S, Ikeuchi M: Phototactic motility in the unicellular cyanobacterium Synechocystis sp. PCC 6803. Photochem Photobiol Sci 2004, 3:512-518.

52. Yoshihara S, Katayama M, Geng X, Ikeuchi M: Cyanobacterial phytochrome-like PixJ1 holoprotein shows novel reversible photoconversion between blue- and green-absorbing forms. Plant Cell Physiol 2004, 45:1729-1737.

53. Narikawa R, Suzuki F, Yoshihara S, Higashi S, Watanabe M, Ikeuchi M: Novel photosensory two-component system (PixA-NixB-NixC) involved in the regulation of positive and negative phototaxis of cyanobacterium Synechocystis sp. PCC 6803. Plant Cell Physiol 2011, 52:2214-2224.

54. Song JY, Cho HS, Cho Jl, Jeon JS, Lagarias JC, Park YI: Near-UV cyanobacteriochrome signaling system elicits negative phototaxis in the cyanobacterium Synechocystis sp. PCC 6803. Proc Natl Acad Sci U S A 2011, 108:10780-10785.

55. Savakis P, De Causmaecker S, Angerer V, Ruppert U, Anders K, Essen LO, Wilde A: Light-induced alteraction of c-di-GMP level controls motility of Synechocystis sp. PCC 6803. Mol Microbiol 2012, 85:239-251.

56. Ng WO, Grossman AR, Bhaya D: Multiple light inputs control phototaxis in Synechocystis sp. PCC6803. J Bacteriol 2003, 185:1599-1607.

57. Yeh KC, Wu SH, Murphy JT, Lagarias JC: A cyanobacterial phytochrome two-component light sensory system. Science 1997, 277:1505-1508.

58. Chen Y, Zhang J, Luo J, Tu JM, Zeng XL, Xie J, Zhou M, Zhao JQ, Scheer H, Zhao KH: Photophysical diversity of two novel cyanobacteriochromes with phycocyanobilin chromophores: photochemistry and dark reversion kinetics. FEBS J 2012, 279:40-54.

59. Giraud E, Zappa S, Vuillet L, Adriano JM, Hannibal L, Fardoux J, Berthomieu C, Bouyer P, Pignol D, Verméglio A: A new type of bacteriophytochrome acts in tandem with a classical bacteriophytochrome to control the antennae synthesis in Rhodopseudomonas palustris. J Biol Chem 2005, 280:32389-32397.

60. Davis SJ, Vener AV, Vierstra RD: Bacteriophytochromes: phytochrome-like photoreceptors from nonphotosynthetic eubacteria. Science 1999, 286:2517-2520.

61. Giraud E, Fardoux J, Fourrier N, Hannibal L, Genty B, Bouyer P, Dreyfus B, Verméglio A: Bacteriophytochrome controls photosystem synthesis in anoxygenic bacteria. Nature 2002, 417:202-205.

62. Tasler R, Moises T, Frankenberg-Dinkel N: Biochemical and spectroscopic characterization of the bacterial phytochrome of Pseudomonas aeruginosa. FEBS J 2005, 272:1927-1936.

63. Frankenberg-Dinkel N: Bacterial heme oxygenases. Antioxid Redox Signal 2004, 6:825-834

64. Alvey RM Biswas A, Schluchter WM, Bryant DA: Attachment of noncognate chromophores to CpcA of Synechocystis sp. PCC 6803 and Synechococcus sp. PCC 7002 by heterologous expression in Escherichia coli. Biochemistry 2011, 50:4890-4902.

65. Shang L, Rockwell NC, Martin SS, Lagarias JC: Biliverdin amides reveal roles for propionate side chains in bilin reductases recognition and in holophytochromes assembly and photoconversion. Biochemistry 2010, 49:6070-6082

66. Rockwell NC, Lagarias JC: A brief history of phytochromes. ChemPhysChem 2010, 11:1172-1180

67. Auldridge ME, Forest KT: Bacterial phytochromes: more than meets the light. Crit Rev Biochem Mol Biol 2011, 46:67-88

68. Jaubert MJ, Lavergne J, Fardoux J, Hannibal L, Vuillet L, Adriano JM, Bouyer $P$, Pignol $D$, Giraud $E$, Verméglio A: A singular bacteriophytochrome acquired by lateral gene transfer. J Biol Chem 2007, 280:7320-7328.

69. Rockwell NC, Martin SS, Lagarias JC: Red/green cyanobacteriochromes: sensors of color and power. Biochemistry 2012, 51:9667-9677.
70. Elías-Arnanz M, Padmanabhan S, Murillo FJ: Light-dependent gene regulation in nonphototrophic bacteria. Curr Opin Microbio/ 2011, 14:128-135.

71. Zusman DR, Scott AE, Yang Z, Kirby JR: Chemosensory pathways, motility and development in Myxococcus xanthus. Nat Rev Microbiol 2007, 5:862-872.

72. Kim YK, McCarter LL: ScrG, a GGDEF-EAL protein, participates in regulating swarming and sticking in Vibrio parahaemolyticus. J Bacteriol 2007, 189:4094-4107.

73. Pfennig N: Syntrophic mixed cultures and symbiotic consortia with phototrophic bacteria: a review. In Anaerobes and anaerobic infections. Edited by Gottschalk G, Werner PN. Stuttgart: Fischer 1980, 1980:127-131.

74. Warthmann $\mathrm{R}$, Cypionka $\mathrm{H}$, Pfennig N: Photoproduction of $\mathrm{H}_{2}$ from acetate by syntrophic cocultures of green sulfur bacteria and sulfur-reducing bacteria. Arch Microbiol 1992, 157:343-348.

75. Gregersen LH, Bryant DA, Frigaard N-U: Mechanisms and evolution of oxidative sulfur metabolism in green sulfur bacteria. Front Microbio 2011 2:116.

76. Andrews SC, Berks BC, McClay J, Ambler A, Quail MA, Golby P, Guest JR: A 12-cistron Escherichia coli operon (hyf) encoding a putative proton-translocating formate hydrogenlyase system. Microbiology 1997, 143:3633-3647

77. Schut GJ, Boyd ES, Peters JW, Adams MW: The modular respiratory complexes involved in hydrogen and sulfur metabolism by heterotrophic hyperthermophilic archaea and their evolutionary implications. FEMS Microbiol Rev 2013, 37:182-203.

78. Vignais PM, Bernard Billoud B, Meyer J: Classification and phylogeny of hydrogenases. FEMS Microbiol Rev 2001, 25:455-501.

79. Meganathan R: Biosynthesis of menaquinone (vitamin K2) and ubiquinone (coenzyme Q): a perspective on enzymatic mechanisms. Vitam Horm 2001, 61:173-218.

80. Hiratsuka T, Furihata K, Ishikawa J, Yamashita H, Itoh N, Seto H, Dairi T: An alternative menaquinone biosynthetic pathway operating in microorganisms. Science 2008, 321:1670-1673.

81. Nowicka B, Kruk J: Occurrence, biosynthesis and function of isoprenoid quinones. Biochim Biophys Acta 2010, 1797:1587-1605.

82. Newman DK, Kolter R: A role for excreted quinones in extracellular electron transfer. Nature 2000, 405:94-97.

83. Rezaïki L, Lamberet G, Derré A, Gruss A, Gaudu P: Lactobacillus lactis produces short-chain quinones that cross-fed Group B Streptococcus to activate respiration growth. Mol Microbiol 2008, 67:947-957.

84. Hojo K, Nagaoka S, Ohshima T, Maeda N: Bacterial interactions in dental biofilm development. J Dent Res 2009, 88:982-990.

85. Reguera G, McCarthy KD, Mehta T, Nicoll JS, Tuominen MT, Lovley DR: Extracellular electron transfer via microbial nanowires. Nature 2005 435:1098-1101.

86. Gorby YA, Yanina S, McLean JS, Rosso KM, Moyles D, Dohnalkova A, Beveridge TJ, Chang IS, Kim BH, Kim KS, Culley DE, Reed SB, Romine MF, Saffarini DA, Hill EA, Shi L, Elias DA, Kennedy DW, Pinchuk G, Watanabe K, Ishii S, Logan B, Nealson KH, Fredrickson JK: Electrically conductive bacterial nanowires produced by Shewanella oneidensis strain MR-1 and other microorganisms. Proc Natl Acad Sci U S A 2006, 103:11358-11363.

87. El-Naggar MY, Wanger G, Leung KM, Yuzvinsky TD, Southam G, Yang J, Lau WM, Nealson KH, Gorby YA: Electrical transport along bacterial nanowires from Shewanella oneidensis MR-1. Proc Natl Acad Sci U S A 2010, 107:18127-18131.

88. Liu YG, Huang N: Efficient amplification of insert end sequences from bacterial artificial chromosome clones by thermal asymmetric interlaced PCR. Plant Mol Biol Rep 1998, 16:175-181.

89. Ewing $B$, Hillier $L$, Wendl M, Green P: Basecalling of automated sequencer traces using phred, I. Accuracy assessment. Genome Res 1998, 8:175-185.

90. Gordon D, Abajian C, Green P: Consed: a graphical tool for sequence finishing. Genome Res 1998, 8:195-202.

91. Liu Z, Frigaard NU, Vogl K, lino T, Ohkuma M, Overmann J, Bryant DA: Complete genome sequence of Ignavibacterium album, a nonphototrophic member of the phylum Chlorobi. Front Microbio 2012, 3:185.

92. Vernikos GS, Parkhill J: Interpolated variable order motifs for identification of horizontally acquired DNA: revisiting the Salmonella pathogenicity islands. Bioinfomatics 2006, 22:2196-2203.

93. Dammeyer T, Bagby SC, Sullivan MB, Chisholm SW, Frankenberg-Dinkel N: Efficient phage-mediated pigment biosynthesis in oceanic cyanobacteria. Curr Biol 2008, 18:442-448. 
94. Tooley AJ, Cai Y-P A, Glazer AN: Biosynthesis of a fluorescent cyanobacterial C-phycocyanin holo-a subunit in a heterologous host. Proc Natl Acad SCi US A 2001, 98:10560-10565.

95. Rockwell NC, Shang L, Martin SS, Lagarias JC: Distinct classes of red/far-red photochemistry within the phytochrome superfamily. Proc Natl Acad Sci U S A 2009, 106:6123-6127.

96. Frigaard N-U, Li H, Milks KJ, Bryant DA: Nine mutants of Chlorobium tepidum each unable to synthesize a different chlorosome protein still assemble functional chlorosomes. J Bacterio/ 2004, 186:646-653.

97. Garcia Costas AM, Tsukatani Y, Rijpstra WI, Schouten S, Welander PV, Summons RE, Bryant DA: Identification of the bacteriochlorophyhlls, carotenoids, quinones, lipids, and hopanoids of "Candidatus Chloracidobacterium thermophilum". J Bacteriol 2012, 194:1158-1168.

\section{doi:10.1186/gb-2013-14-11-r127}

Cite this article as: Liu et al:: Genomic analysis reveals key aspects of prokaryotic symbiosis in the phototrophic consortium

"Chlorochromatium aggregatum". Genome Biology 2013 14:R127.

\section{Submit your next manuscript to BioMed Central and take full advantage of:}

- Convenient online submission

- Thorough peer review

- No space constraints or color figure charges

- Immediate publication on acceptance

- Inclusion in PubMed, CAS, Scopus and Google Scholar

- Research which is freely available for redistribution 